\title{
Film models for transport phenomena with fog formation: the fog film model
}

\author{
H. J. H. BROUWERS \\ Akzo Research Laboratories Arnhem, Fibers Division, Department of Mechanical Engineering, \\ Velperweg 76, 6824 BM Arnhem, The Netherlands
}

(Received 29 August 1990)

\begin{abstract}
In a preceding paper (Brouwers and Chesters, Int. J. Heat Mass Transfer 35, I-11 (1992)) possible supersaturation in a film and in the bulk of a binary mixture has been discussed. In the present analysis the exact conditions for fog formation and the magnitude of the fogging and superheated regions in the film are first determined. Next, the governing equation of diffusion and energy (coupled with the saturation condition) of the fog layer is solved numerically. An evaluation of various mixtures of water vapour and air illustrates the substantial effect of fog formation on heat and mass transfer rates. Subsequently, a thorough asymptotic analysis of the fog layer's governing equation yields an excellently matching approximation solution. Furthermore, this solution leads to analytical film model correction factors for the combined effects of fog formation and injection/suction on transfer rates. Finally, the fog film model is applied to channel flow of a binary mixture. This approach provides new procedures for the computation of condensers and evaporators, allowing both fog formation in the film (affecting transfer rates) and/or in the bulk (affecting the incremental balances of mass and energy).
\end{abstract}

\section{INTRODUCTION}

IN THE film considered in the previous paper [1] fog can be formed, if the temperature and vapour fraction profiles cross the saturation line. The classical film model analysis with resulting correction factors is then no longer valid and applicable, since in the supersaturated film the energy and diffusion equation are altered.

Supersaturation in mixtures has bcen the subjcct of many studies in the past, relevant contributions are discussed briefly in the following. Piening [2] observed no fog formation in slightly supersaturated clean airwater vapour mixtures, owing to the absence of foreign nuclei. Based on homogeneous nucleation at a critical supersaturation level, numerous problems concerning supersaturated gas mixtures have been treated. Turkdogan [3] and Turkdogan and Mills [4] introduced the 'critical supersaturation model' (CSM) to describe the wall evaporation of metals into a helium atmosphere. For the same purpose this CSM has been employed and extended by Rosner [5], by Rosner and Epstein [6] and Sekulic̀ [7] to model wall condensation of water vapour in moist air, by Epstein and Rosner [8] to investigate methyl alcohol evaporation into an air atmosphere, and by Hayashi et al. $[9,10]$ to describe the naphthalene sublimation into air.

In an carly paper, Johnstonc et al. [11] observed, if sufficient foreign nuclei are present, that fog formation sets in as soon as supersaturation takes place. Assuming no supersaturation to be possible, the socalled saturation condition, they derived an erroneous expression to investigate the conditions for fog formation [12]. The saturation condition has been employed fruitfully by Hills and Szekely [13, 14], Toor
$[15,16]$ and Aref 'yev and Averkiyev [17] to investigate one-dimensional film systems. Forced convective wall condensation of water vapour in air has been modelled two-dimensionally by Hijikata and Mori [18], Legay-Desesquelles and Prunet-Foch $[19,20]$, and Hayashi et al. [21]. Free convective wall condensation of water vapour in moist air has been studied successfully with the saturation condition by Koch [22].

The central point of interest in all mentioned elaborations, except ref. [17], is the absence of a film analysis including fog formation and an appreciable induced velocity. But in a previous paper it was demonstrated that in many practical situations the induced velocity plays a role of major importance, and that the basic film model approach is well suited to account for this velocity [1]. In their original paper Aref'yev and Averkiyev [17] presented a film analysis of a mixture consisting of air and water vapour under evaporation conditions. Saturated bulk conditions and equal thermal and diffusional film thicknesses were considered and hence the entire film was assumed to be saturated. Their numerical results indicated the significant effect of fog formation on heat and mass transfer rates. However, superheated bulk conditions and the possible existence of both superheated and saturated regions in the film were not considered, nor the application of the fog film model to channel flow.

In this paper therefore a complete film model analysis is presented, whereby a supcrheated bulk and unequal film thicknesses are allowed. First, the conditions for fog formation are analysed thoroughly. Subsequently, the existence and magnitude of superheated and saturated regions in the film are determined precisely, illustrating the role of the decisive parameter $L e_{v}$ (it will be demonstrated that superheating in the film is possible for $L e_{\mathrm{v}}<1$, not- 


\section{NOMENCLATURE}

c vapour mass fraction

$c_{p} \quad$ specific heat $\left[\mathrm{J} \mathrm{kg}^{-1} \mathrm{~K}^{-1}\right]$

Di diffusion coefficient $\left[\mathrm{m}^{2} \mathrm{~s}^{-1}\right]$

$D_{\mathrm{h}} \quad$ hydraulic diameter; four times the crosssectional area divided by the perimeter of the channel [m]

$F \quad$ saturation vapour mass fraction

$G \quad$ relation between $c$ and $t$ in superheated region

$g_{m} \quad$ mass transfer coefficient $\left[\mathrm{kg} \mathrm{m}^{-2} \mathrm{~s}^{-1}\right]$

$H$ fog condition function, see equation (A4)

$H_{\text {lat }} \quad$ latent heat of condensation [ $\mathrm{J} \mathrm{kg}^{-1}$ ]

$h_{\mathrm{g}} \quad$ heat transfer coefficient [ $\mathrm{W} \mathrm{m}^{-2} \mathrm{~K}^{-1}$ ]

$K$ fog formation per unit volume $\left[\mathrm{kg} \mathrm{m}^{-3} \mathrm{~s}^{-1}\right]$

$k$ thermal conductivity [W m ${ }^{-1} \mathrm{~K}^{-1}$ ]

Le Lewis number, $k / \rho c_{p} \mathbb{D}$

$L e_{\mathrm{v}} \quad$ modified Lewis number, $k / \rho c_{p, v} \mathbb{D}$

$M \quad$ mass of $1 \mathrm{kmol}$ of substance [kg]

$\dot{M}_{\text {r }}$ dimensionless fog formation, defined by equation (30)

$\dot{m} \quad$ mass flux at wall $\left[\mathrm{kg} \mathrm{m}^{-2} \mathrm{~s}^{-1}\right]$

$\dot{m}_{\mathrm{f}} \quad$ fog mass flux in film $\left[\mathrm{kg} \mathrm{m}^{-2} \mathrm{~s}^{-1}\right]$

$N u \quad$ Nusselt number, $h_{\mathrm{g}} D_{\mathrm{h}} / k$

$P \quad$ pressure [bar]

$q$ heat flux at wall [ $\mathrm{W} \mathrm{m}^{-2}$ ]

Sh Sherwood number, $g_{m} D_{\mathrm{h}} / \rho \mathbb{D}$

$t$ temperature $\left[{ }^{\circ} \mathrm{C}\right]$ $u \quad$ component of velocity in the direction of

$x\left[\mathrm{~m} \mathrm{~s}^{-1}\right]$

$x \quad$ coordinate $[\mathrm{m}]$

$Y$ dimensionless coordinate, $y / \delta_{\mathrm{a}}$

$y$ coordinate $[\mathrm{m}]$.

Greek symbols

$\delta \quad$ film thickness [m]

$\Theta \quad$ correction factor

$\rho$ density $\left[\mathrm{kg} \mathrm{m}^{-3}\right]$.

Subscripts

a border of saturated and superheated region

b bulk

$c$ diffusional

f fog

f1 pertaining to numerical fog film model

f2 pertaining to asymptotic fog film model

i interface

n non-condensables

$t$ thermal

tot total

v vapour.

Superscripts

inv inverse

- mean fixed or 'bulk'. withstanding a saturated bulk). The governing equation of diffusion and energy in the fogging region, coupled with the saturation condition, is first solved numerically. The possible existence of both a saturated and superheated region in the film, and the effect of fog formation on heat and mass transfer, is illustrated in various saturated air-water vapour mixtures.

Next, an asymptotic analysis is carried out, yielding an excellent approximate solution of the fog layer's governing non-linear equation. This solution supplies reliable analytical expressions for the correction factors, which are suitable for the dimensioning of heat exchanging devices, such as condensers or evaporators. The application of the fog film model to channel flow is demonstrated in detail and illustrated by means of a flow chart.

\section{FILM ANALYSIS}

In this section the heat and mass transfer in a film as described in ref. [1] is analysed and extended to include the possibility of fog formation. An elementary study of the vapour mass fraction and gas temperature profiles in the film yield the exact circumstances needed for formation. The alternative diffusion and energy equation, in the case of fog formation coupled with the saturation condition, are then derived and solved numerically. Correction factors are then introduced which will be compared in the next section with the correction factors for the conventional film model without fog formation.

The connection between the vapour concentration $c$ and the temperature $t$ in the film of a binary mixture was derived in ref. [1] ('equation (50)'). This curve can be located such that it crosses the saturation line $F(t)$ of the vapour. The possible intersection of $G(t)$ and $F(t)$, enabling the formation of fog, is now examined by condensing the slope conditions

$$
\begin{aligned}
\left.\frac{\mathrm{d} F}{\mathrm{~d} t}\right|_{t_{\mathrm{i}}}<\left.\frac{\mathrm{d} G}{\mathrm{~d} t}\right|_{t_{\mathrm{i}}}= & L e_{\mathrm{v}} \frac{c_{\mathrm{i}}-1}{t_{\mathrm{b}}-t_{\mathrm{i}}} \\
& \times\left[\exp \left\{\frac{\delta_{t}}{L e_{\mathrm{v}} \delta_{c}} \ln \left(\frac{1-c_{\mathrm{b}}}{1-c_{\mathrm{i}}}\right)\right\}-1\right]
\end{aligned}
$$

for suction and, with a rearranged right-hand side

$$
\left.\frac{\mathrm{d} F}{\mathrm{~d} t}\right|_{t_{\mathrm{i}}}>\left.\frac{\mathrm{d} G}{\mathrm{~d} t}\right|_{t_{\mathrm{i}}}=\frac{\delta_{r}}{\delta_{c}} \frac{\Theta_{c}}{\Theta_{t}} \frac{c_{\mathrm{b}}-c_{\mathrm{j}}}{t_{\mathrm{b}}-t_{\mathrm{i}}}
$$

for injection. In equation (2) the conventional film model correction factors have been inserted [1]. When 
equations (1) and (2) are not satisfied, the curve $G(t)$ is situated entirely in the superheated region, and no fog will be formed. Consequently, the classical film model corrections remain valid. However, when these requirements are not satisfied, the curve $G(t)$ intersects the saturation line. Assuming no supersaturation to be possible, fog will then be formed in part, or all of the film. The use and limitation of criteria (1) and (2) are discussed in detail in ref. [23]. The film, superheated and/or saturated, is analysed below.

The first step is to divide the film into a fog or saturated layer $\left(0 \leqslant y \leqslant \delta_{\mathrm{a}}\right)$ and a superheated layer $\left(\delta_{\mathrm{a}} \leqslant y \leqslant \delta_{c}\right.$ or $\left.\delta_{t}\right)$. The fog layer thickness $\delta_{\mathrm{a}}$ lies between zero (i.e. no fog formation) and $\delta_{c}$ or $\delta_{t}$, when the entire film is saturated. But $\delta_{\mathrm{a}}$ is at present unknown and will be determined later on. Plural saturated and superheated regions in the film have been excluded implicitly, though it is demonstrated in ref. [23] that this feature cannot be proved mathematically for $L e_{\mathrm{v}}<1$. Secondly, at the boundary of the superheated and saturated regions the temperature is denoted by

$$
t\left(y=\delta_{\mathrm{a}}\right)=t_{\mathrm{a}}
$$

and the vapour mass fraction must obey the requirement

$$
c\left(y=\delta_{\mathrm{a}}\right)=c_{\mathrm{a}} .
$$

The vapour mass fraction up to and including the boundary of the saturated region is related to the temperature by the saturation condition

$$
c=F(t) \quad\left(t_{\mathrm{i}} \leqslant t \leqslant t_{\mathrm{a}}\right) .
$$

This so-called saturation condition has been utilized in view of its convenience and accuracy to most practical situations.

In the analysis of the fog layer the droplets created (and transported, e.g. by thermophoresis) are not explicitly considered and the physical properties in the superheated and saturated mixture are therefore assumed to be identical. This approach is quite acceptable since the fraction of droplets in mixtures is usually very small.

In the superheated region the diffusion equation and induced velocity of ref. [1] are still valid. Solving this equation with the appropriate boundary con ditions (4) and $c\left(y=\delta_{c}\right)=c_{\mathrm{b}}$ yields

$$
\begin{gathered}
c(y)=1-\left(1-c_{\mathrm{a}}\right) \exp \left\{\frac{y-\delta_{\mathrm{a}}}{\delta_{c}-\delta_{\mathrm{a}}} \ln \left(\frac{1-c_{\mathrm{b}}}{1-c_{\mathrm{a}}}\right)\right\} \\
\left(\delta_{\mathrm{a}} \leqslant y \leqslant \delta_{c}\right) .
\end{gathered}
$$

The temperature distribution is obtained by solving the energy equation of the film with application of boundary condition (3) and the value of $t\left(y=\delta_{t}\right)=$ $t_{\mathrm{b}}$, resulting in the temperature profile

$$
\begin{aligned}
& t(y)=\left(t_{\mathrm{b}}-t_{\mathrm{a}}\right) \\
& \times\left[\frac{\exp \left\{\frac{y-\delta_{\mathrm{a}}}{L e_{\mathrm{v}}\left(\delta_{c}-\delta_{\mathrm{a}}\right)} \ln \left(\frac{1-c_{\mathrm{b}}}{1-c_{\mathrm{a}}}\right)\right\}-1}{\exp \left\{\frac{\delta_{t}-\delta_{\mathrm{a}}}{L e_{\mathrm{v}}\left(\delta_{c}-\delta_{\mathrm{a}}\right)} \ln \left(\frac{1-c_{\mathrm{b}}}{1-c_{\mathrm{a}}}\right)\right\}-1}\right]+t_{\mathrm{a}} \\
&\left(\delta_{\mathrm{a}} \leqslant y \leqslant \delta_{t}\right) .
\end{aligned}
$$

Eliminating $\left(y-\delta_{\mathrm{a}}\right) /\left(\delta_{c}-\delta_{\mathrm{a}}\right)$ from equations (6) and (7) results in the following relation between $c$ and $t$ in the superheated region:

$$
\begin{array}{ll}
\delta_{c}<\delta_{t} \begin{cases}c=G(t)=1+\left(c_{\mathrm{a}}-1\right)\left(\frac{t-t_{\mathrm{a}}}{t_{\mathrm{b}}-t_{\mathrm{a}}}\left[\exp \left\{\frac{\delta_{t}-\delta_{\mathrm{a}}}{L e_{\mathrm{v}}\left(\delta_{c}-\delta_{\mathrm{a}}\right)} \ln \left(\frac{1-c_{\mathrm{b}}}{1-c_{\mathrm{a}}}\right)\right\}-1\right]+1\right)^{2 e_{\mathrm{v}}} & \left(t_{\mathrm{a}} \leqslant t \leqslant t\left(y=\delta_{c}\right)\right) \\
c=c_{\mathrm{b}} & \left(t\left(y=\delta_{c}\right) \leqslant t \leqslant t_{\mathrm{b}}\right)\end{cases} \\
\delta_{c}=\delta_{t}: c=G(t)=1+\left(c_{\mathrm{a}}-1\right)\left(\frac{t-t_{\mathrm{a}}}{t_{\mathrm{b}}-t_{\mathrm{a}}}\left[\exp \left\{\frac{1}{L e_{\mathrm{v}}} \ln \left(\frac{1-c_{\mathrm{b}}}{1-c_{\mathrm{a}}}\right)\right\}-1\right]+1\right)^{L e_{\mathrm{v}}} & \left(t_{\mathrm{a}} \leqslant t \leqslant t_{\mathrm{b}}\right)
\end{array}
$$$$
\delta_{c}>\delta_{t}\left\{\begin{array}{l}
c=G(t)=1+\left(c_{\mathrm{a}}-1\right)\left(\frac{t-t_{\mathrm{a}}}{t_{\mathrm{b}}-t_{\mathrm{a}}}\left[\exp \left\{\frac{\delta_{t}-\delta_{\mathrm{a}}}{L e_{\mathrm{v}}\left(\delta_{c}-\delta_{\mathrm{a}}\right)} \ln \left(\frac{1-c_{\mathrm{b}}}{1-c_{\mathrm{a}}}\right)\right\}-1\right]+1\right)^{L e_{\mathrm{v}}} \quad\left(t_{\mathrm{a}} \leqslant t \leqslant t_{\mathrm{b}}\right) \\
c \text { is not a function of } t \text { for } \delta_{t}<y \leqslant \delta_{c}
\end{array}\right.
$$

frequently in the past, as discussed in the Introduction. The saturation condition holds in general when sufficient particles are present in the mixture which can serve as nuclei for condensation. According to Steinmeyer [24] these conditions are indeed often fulfilled in practical situations. The level of supersaturation, which thermodynamically must always be non-zero, can then be considered as negligibly small. Moreover, for the analysis it is in fact not relevant which relation between $c$ and $t$ in the fog region is selected, which is to say that $F(t)$ can also be the result of a CSM, here the saturation condition is employed
For $\delta_{\mathrm{a}}=0$ (i.e. $t_{\mathrm{a}}=t_{\mathrm{i}}$ and $c_{\mathrm{a}}=c_{\mathrm{i}}$ ) solutions (6) (8) reduce to the solutions of the convectional film [1].

At the boundary of the saturated and superheated region the concentration and temperature (and physical properties) are continuous, as are the energy and mass flux

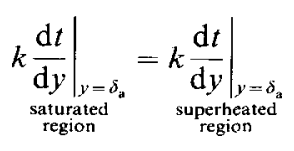




$$
\left.\frac{\rho \mathbb{D}}{1-c} \frac{\mathrm{d} c}{\mathrm{~d} y}\right|_{\substack{y=\delta_{\mathrm{a}} \\ \text { regiona }}}=\left.\frac{\rho \mathbb{D}}{1-c} \frac{\mathrm{d} c}{\mathrm{~d} y}\right|_{\substack{\text { superteated } \\ \text { region }}} .
$$

The temperature and vapour concentration in the superheated region are already known, see equations (6) and (7), but in the saturated region they have yet to be determined. However, in the saturated region the concentration and temperature are coupled by the saturation function (5). Combining equations (9) and (10) to eliminate the $y$-dependence and applying equations (5) and (8) yields as tangency condition

$$
\begin{aligned}
\left.\frac{\mathrm{d} F}{\mathrm{~d} t}\right|_{t_{\mathrm{a}}}= & \left.\frac{\mathrm{d} G}{\mathrm{~d} t}\right|_{t_{\mathrm{a}}}=L e_{\mathrm{v}} \frac{c_{\mathrm{a}}-1}{t_{\mathrm{b}}-t_{\mathrm{a}}} \\
& \times\left[\exp \left\{\frac{\delta_{t}-\delta_{\mathrm{a}}}{L e_{\mathrm{y}}\left(\delta_{t}-\delta_{\mathrm{a}}\right)} \ln \left(\frac{1-c_{\mathrm{b}}}{1-c_{\mathrm{a}}}\right)\right\}-1\right] .
\end{aligned}
$$

Equation (11) prescribes continuity of the first derivative $\mathrm{d} c / \mathrm{d} t$ as given by equation (8) in the superheated region and by equation (5) in the fog layer. Additional information about the use and features of equation (11) is given in ref. [23]. Equation (11) contains two unknowns, namely $t_{\mathrm{a}}$ and $\delta_{\mathrm{a}}$ (since $c_{\mathrm{a}}=F\left(t_{\mathrm{a}}\right)$ ). In order to derive a second equation with both unknowns and to complete the analysis of the film, attention is now focused on the fog layer next to the wall $\left(0 \leqslant y \leqslant \delta_{a}\right)$.

In the fog layer vapour disappears by spontaneous condensation and as a result of the droplet formation latent heat is liberated. In this layer the energy and diffusion equation read

$$
\begin{aligned}
& k \frac{\mathrm{d}^{2} t}{\mathrm{~d} y^{2}}+\frac{\rho \mathbb{D} c_{p, v}}{1-c} \frac{\mathrm{d} c}{\mathrm{~d} y} \frac{\mathrm{d} t}{\mathrm{~d} y}=-H_{\mathrm{lat}} K \\
& \rho \mathbb{D} \frac{\mathrm{d}^{2} c}{\mathrm{~d} y^{2}}+\frac{\rho \mathbb{D}}{1-c} \frac{\mathrm{d} c}{\mathrm{~d} y} \frac{\mathrm{d} c}{\mathrm{~d} y}=K(1-c)
\end{aligned}
$$

with as respective boundary conditions $t(y=0)=t_{\mathrm{i}}$ and equation (3), and $c(y=0)=c_{\mathrm{i}}$ and equation (4). In equations (12) and (13) $K$ represents the mass of fog formed in the mixture per unit volume. Eliminating $K$ from these equations produces

$$
L e_{\mathrm{v}} \frac{\mathrm{d}^{2} t}{\mathrm{~d} y^{2}}-\frac{\mathrm{d} \ln (1-c)}{\mathrm{d} y} \frac{\mathrm{d} t}{\mathrm{~d} y}=\frac{H_{\text {lat }}}{c_{p, \nu}} \frac{\mathrm{d}^{2} \ln (1-c)}{\mathrm{d} y^{2}} .
$$

This equation is an ordinary non-linear second-order differential equation in $t$ with respect to the coordinate $y$, sincc $c$ is cxpresscd by the saturation cquation (5) as a function of $t$. As a soiution in closed form is not possible, the boundary value problem (14), with boundary conditions $t(y=0)=t_{\mathrm{i}}$ and equation (3), is solved numerically with a standard shooting method. Detailed information about this solution technique is found in Hall and Watt [25]. In order to prepare equation (14) for this solution method, the dimensionless variable

$$
Y=\frac{y}{\delta_{\mathrm{a}}}
$$

is substituted into equation (14). By this substitution equation (14) remains in exactly the same form, but the domain of integration is transformed into $0 \leqslant Y \leqslant 1$.

The second equation containing $t_{\mathrm{a}}$ and $\delta_{\mathrm{a}}$ is now obtained by combining the numerical solution of equation (14), and equations (7), (9) and (15)

$$
\begin{aligned}
\frac{\delta_{c}}{\delta_{\mathrm{a}}}=1 & +\frac{1}{\left.L e_{\mathrm{v}} \frac{\mathrm{d} t}{\mathrm{~d} Y}\right|_{Y=1}} \\
& \times\left[\frac{\left(t_{\mathrm{b}}-t_{\mathrm{a}}\right) \ln \left(\frac{1-c_{\mathrm{b}}}{1-c_{\mathrm{a}}}\right)}{\exp \left\{\frac{\delta_{t}-\delta_{\mathrm{a}}}{L e_{\mathrm{v}}\left(\delta_{c}-\delta_{\mathrm{a}}\right)} \ln \left(\frac{1-c_{\mathrm{b}}}{1-c_{\mathrm{a}}}\right)\right\}-1}\right]
\end{aligned}
$$

The combined iteration of equations (11) and (16) yields $\delta_{\mathrm{a}}$ and $t_{\mathrm{a}}$. To employ this simultaneous iteration the boundary problem (14) has to be solved for every value of $t_{a}$ during the iteration. To decouple both equations and reduce the computational effort, the equality $\delta_{t}=\delta_{c}$ could from now on be supposed to be valid. Rather than setting $N u=S h$, though it is acceptable for many transfer processes, the magnitude of the term $\left(\delta_{t}-\delta_{\mathrm{a}}\right) /\left(\delta_{c}-\delta_{\mathrm{a}}\right)$ is evaluated in the following.

In the case in which no fog is formed in the film, so that $K$ is identically zero in equation (13), the vapour mass fraction, $c_{\mathrm{a}}$, at location $y=\delta_{\mathrm{a}}$ is given by

$$
\frac{\delta_{c}}{\delta_{c}-\delta_{\mathrm{a}}}=\frac{\ln \left(1-c_{\mathrm{b}}\right)-\ln \left(1-c_{\mathrm{i}}\right)}{\ln \left(1-c_{\mathrm{b}}\right)-\ln \left(1-c_{\mathrm{a}}\right)}
$$

since then $\ln (1-c)$ depends linearly on $y$ in both the saturated and superheated region. If equation (17) is supposed to be valid when fog is present and is inserted into equation (11), $\delta_{\mathrm{a}}$ is eliminated from the right-hand sides of equations (11) and (16). Hence, equation (11) produces readily $t_{\mathrm{a}}$, and with this $t_{\mathrm{a}}$ equation (14) is solved, and with the numerical solution $\delta_{\mathrm{a}}$ is obtained explicitly from equation (16). A similar simplification follows in fact from inserting $\delta_{t}=\delta_{c}$, as discussed above.

However, equation (17) is only an approximation when $K \neq 0$ and the error involved by assuming equation (17) has to be assessed. The amount of formed fog has been derived in the Appendix. It has furthermore been discussed in ref. [23] that the amount of fog produced is greatest where the temperature of the fog layer is lowest. For evaporation this temperature corresponds to $t_{\mathrm{a}}$, while for condensation this temperature is found at the interface, thus $t=t_{\mathrm{i}}$. Equation (17) is violated the most if this maximum value of $K$ is supposed to apply throughout the entire fog region. Integrating equation (13) twice with respect to $y$, and application of boundary conditions $c(y=0)=c_{\mathrm{i}}$ and equation (4) then yields 


$$
\begin{array}{r}
\ln (1-c(y))=-\frac{1}{2} p\left(\frac{y}{\delta_{\mathrm{a}}}\right)^{2}+\left(\ln \left(\frac{1-c_{\mathrm{a}}}{1-c_{\mathrm{i}}}\right)+\frac{1}{2} p\right) \frac{y}{\delta_{\mathrm{a}}} \\
+\ln \left(1-c_{\mathrm{i}}\right) \quad\left(0 \leqslant y \leqslant \delta_{\mathrm{a}}\right)
\end{array}
$$

where $p$ follows from equations (15) and (A3)

$$
\begin{aligned}
& p=\frac{\delta_{\mathrm{a}}^{2}}{\rho \mathbb{D}} K \\
& =\frac{\left(L e_{\mathrm{v}}-1\right)\left(\frac{1}{1-F} \frac{\mathrm{d} F}{\mathrm{~d} t}\right)^{2}+L e_{\mathrm{v}} \frac{1}{1-F} \frac{\mathrm{d}^{2} F}{\mathrm{~d} t^{2}}}{L e_{\mathrm{v}}+\frac{H_{\text {lat }}}{c_{p, \mathrm{v}}} \frac{1}{1-F} \frac{\mathrm{d} t}{\mathrm{~d} t}}
\end{aligned}
$$

The relation between film thicknesses and vapour fraction follows from combining equations (6), (10) and (18), yielding

$$
\frac{\delta_{c}}{\delta_{c}-\delta_{\mathrm{a}}}=\frac{\ln \left(1-c_{\mathrm{b}}\right)-\ln \left(1-c_{\mathrm{i}}\right)}{\ln \left(1-c_{\mathrm{b}}\right)-\ln \left(1-c_{\mathrm{a}}\right)}(1+\varepsilon)
$$

with

$$
\varepsilon=\frac{\frac{1}{2} p}{\ln \left(1-c_{\mathrm{b}}\right)-\ln \left(1-c_{\mathrm{i}}\right)}
$$

as a measure of the error occasioned by assuming equation (17). Equation (17) is rewritten as

$$
\frac{\delta_{t}-\delta_{\mathrm{a}}}{\delta_{c}-\delta_{\mathrm{a}}}=1+\left(\frac{\delta_{t}}{\delta_{c}}-1\right) \frac{\ln \left(1-c_{\mathrm{b}}\right)-\ln \left(1-c_{\mathrm{i}}\right)}{\ln \left(1-c_{\mathrm{b}}\right)-\ln \left(1-c_{\mathrm{a}}\right)}
$$

For wall evaporation the actual effect of $\delta_{t} \neq \delta_{c}$ is greater than expressed by this equation and equation (17), as $\varepsilon>0$, while for condensation equations (17) and (22) exaggerate this effect, since then $\varepsilon<0$. However, equation (22) reckons to some extent with unequal thermal and diffusional film thicknesses, while its application decouples equations (11) and (16) and therefore reduces the computational effort. From now on $\varepsilon$ is therefore considered to be zero, the actual magnitude of $\varepsilon$ is assessed in the next section for some practical situations.

The correction factors of heat and mass transfer will now be derived. With equation (15) the transferred heat is written as

$$
q=\left.\frac{k}{\delta_{\mathrm{a}}} \frac{\mathrm{d} t}{\mathrm{~d} Y}\right|_{Y=0} .
$$

Comparing equation (23) with the heat flux in a film without fog and without induced velocity, yields as correction factor

$$
\Theta_{t, \mathrm{f}}=\frac{\left.\frac{\delta_{t}}{\delta_{\mathrm{a}}} \frac{\mathrm{d} t}{\mathrm{~d} Y}\right|_{Y=0}}{\left(t_{\mathrm{b}}-t_{\mathrm{i}}\right)} .
$$

Combining the mass flux from gas to wall and equation (5) results in

$$
\dot{m}=\left.\left.\frac{\rho \mathbb{D}}{1-F\left(t_{\mathrm{i}}\right)} \frac{\mathrm{d} F}{\mathrm{~d} t}\right|_{t_{\mathrm{i}}} \frac{\mathrm{d} t}{\mathrm{~d} y}\right|_{y=0} .
$$

Application of equations (15) and (25) results in the following correction factor for diffusion :

$$
\Theta_{c, \mathrm{f}}=\frac{\left.\left.\frac{\delta_{c}}{\delta_{\mathrm{a}}} \frac{\mathrm{d} F}{\mathrm{~d} t}\right|_{t_{\mathrm{i}}} \frac{\mathrm{d} t}{\mathrm{~d} Y}\right|_{Y=0}}{\left(c_{\mathrm{b}}-c_{\mathrm{i}}\right)} .
$$

The gradient of temperature at $Y=0$, appearing in equations (23), (24) and (26), follows from the numerical solution of equation (14). It can easily be verified that in general between the fog correction factors for mass and heat transfer, $\Theta_{c, f}$ and $\Theta_{t, f}$, respectively, the following relation exists:

$$
\Theta_{c, \mathrm{f}}-\left.\frac{t_{\mathrm{b}}-t_{\mathrm{i}}}{c_{\mathrm{b}}-c_{\mathrm{i}}} \frac{\mathrm{d} F}{\mathrm{~d} t}\right|_{t_{\mathrm{i}}} \frac{\delta_{c}}{\delta_{t}} \Theta_{t, \mathrm{f}}
$$

owing to the saturation condition (5) in the fog layer.

An additional interesting property which can be determined with the numerical solution of the combined energy and diffusion equation (14) is the amount of fog formed in the saturated layer

$$
\dot{m}_{\mathrm{f}}=\int_{y=0}^{\delta_{\mathrm{a}}} K \mathrm{~d} y .
$$

Applying equations (12) and (15), equation (28) yields

$$
\begin{aligned}
\dot{m}_{\mathrm{f}}=\frac{k}{H_{\mathrm{lat}} \delta_{\mathrm{a}}}\left(\left.\frac{\mathrm{d} t}{\mathrm{~d} Y}\right|_{Y=0}-\left.\frac{\mathrm{d} t}{\mathrm{~d} Y}\right|_{Y=1}\right. \\
\left.-\frac{1}{L e_{\mathrm{v}}} \int_{Y=0}^{1} \frac{1}{1-c} \frac{\mathrm{d} c}{\mathrm{~d} Y} \frac{\mathrm{d} t}{\mathrm{~d} Y} \mathrm{~d} Y\right) .
\end{aligned}
$$

The first derivatives of $t$ with respect to $Y$ in $Y=0$ and follow from the numerical solution of equation (14); this solution is also employed to calculate numerically the integral in equation (29) with Simpson's rule.

The amount of fog formed, represented by equation (28), is the same for evaporation and condensation, which is explained as follows. Equation (14) remains in the same form when $y$ is replaced by the coordinate $\delta_{\mathrm{a}}-y$, only boundary conditions $t(y=0)=t_{\mathrm{i}}$ and (3) being exchanged. In other words, evaporation conditions become condensation conditions, or vice versa. The solution of equation (14) with exchanged boundary conditions is therefore the reflection of the original equation's solution in the line $y=0.5 \delta_{\mathrm{a}}$, hence $t(y)$ curves for evaporation and condensation are symmetrical with respect to the line $y=0.5 \delta_{\mathrm{a}}$. A similar consideration of equations (28) and (13) provides evidence that the amount of fog formed for condensation and evaporation is positive and equal.

A complete analysis has been given in this section of a film with possible formation of fog. Equation (1) or (2) serves to examine whether fog is formed; when this is the case tangency condition (11), combined with approximation (22), provides the boundary of the saturated and superheated regions $\left(t_{\mathrm{a}}, c_{\mathrm{a}}\right)$. Ultimately, the numerical solution of the governing equation (14) provides the temperature and coupled 
vapour concentration in the saturated region, yielding the fog layer's thickness (16), the correction factors (24) and (26), and the quantity of fog formed (29).

\section{RESULTS OF NUMERICAL SOLUTION}

The influence of fog formation on heat and mass transfer will be greatest when the entire film is saturated. That is to say, when the bulk temperature $t_{\mathrm{b}}$ and bulk vapour fraction $c_{\mathrm{b}}$ are situated on the saturation line. In a condenser or evaporator this condition corresponds to a saturated mixture entering and flowing through a channel. To indicate the effect of fog formation results are presented based on the model derived in the previous section. As an example, saturated air-water vapour mixtures at low temperatures and vapour mass fractions are considered, as well as saturated mixtures at high temperatures and vapour fractions. Both mixtures are examined under condensation conditions, thus $c_{\mathrm{b}}>c_{\mathrm{i}}$, and equal thermal and diffusion film thicknesses. The former conditions are for instance found in air-conditioning devices, while the latter are typical of condensers.

For the first case considered, $\left(t_{i}, c_{j}\right)$ is set equal to $\left(20^{\circ} \mathrm{C}, 0.0144\right)$; this point is situated on the saturation line of an air-water vapour mixture under atmospheric conditions, as derived in the Appendix. The bulk values $\left(t_{\mathrm{b}}, c_{\mathrm{b}}\right)$ are successively set equal to $\left(30^{\circ} \mathrm{C}\right.$, $0.0264)$ and $\left(60^{\circ} \mathrm{C}, 0.1318\right)$, all situated on the same saturation function. The latent to specific heat ratio $H_{\text {lat }} / c_{p, v}$ of water vapour is set equal to $1200 \mathrm{~K}$. Calculations are carried out for $L e_{\mathrm{v}}=0.5,0.75,1$ and 1.25 .

Evaluating equation (11) showed that for all cases the entire film is fogged, thus $\delta_{\mathrm{a}}=\delta_{c}=\delta_{t}$ and $\left(t_{\mathrm{a}}\right.$, $\left.c_{\mathrm{a}}\right)=\left(t_{\mathrm{b}}, c_{\mathrm{b}}\right)$. Substituting the greatest $t_{\mathrm{b}}$ in cquation (A4) produces as maximum $H\left(t_{\mathrm{b}}=60^{\circ} \mathrm{C}\right)=0.13$, which is well below the smallest $L e_{\mathrm{v}}$, namely $L e_{\mathrm{v}}=0.5$. The aforesaid values assure that $L e_{\mathrm{v}}>H(t)$ in all considered fogging films, which is a condition for $K>0$, see the Appendix. In Table 1 the correction factors according to equations (24) and (26), compared with the conventional correction factors, are listed. In this table the dimensionless fog formation is also inserted

$$
\dot{M}_{\mathrm{f}}=\frac{\delta_{t} \dot{m}_{\mathrm{f}} H_{\mathrm{lat}}}{k\left(t_{\mathrm{b}}-t_{\mathrm{i}}\right)}
$$

This number is the ratio of transported sensible heat (heat transferred by conduction) through the film, in the case of no fog formation and no induced velocity, to created latent heat in the film by fog formation and in the presence of an induced velocity.

The large deviation of the correction factor ratios from unity illustrates the substantial influence of fog formation on both heat and mass transfer. The sensible heat transfer ratio is larger than unity, which would be expected since spontaneous condensation in the film causes extra sensible heat generation. This condensation is at the expense of the diffusional vapour transport from bulk to wall. Indeed the ratio of the diffusion correction factors is smaller than unity. For small vapour mass fractions, the latent (this is heat transferred by transport of vapour and liberation of latent heat) and sensible heat transfer in a heat exchanger are of the same magnitude. Because both kinds of heat transfer are seriously affected by fog formation, it is interesting to calculate the total amount of transferred latent and sensible heat from film to wall :

$$
q_{\mathrm{tot}}=q+\dot{m} H_{\mathrm{lat}}
$$

for the classical film model and fog film model. In Table 1 the ratio of $q_{\text {tot }}$ according to the numerical solution and according to the conventional film model is listed. All tabled values are close to unity, implying the total amount of transported heat is hardly altered by fog formation, only the contribution of latent and sensible heat is different. Toor [15] derived analytically that in a film without induced velocity, $1-c_{\mathrm{i}} \cong 1$ and $L e-1$, the ratio of transferred heat is exactly equal to unity. As the physical situations of Table 1 are similar, one can conclude that the numerically obtained ratios are in agreement with the aforesaid analytical result.

The maximum error introduced by assumption (17) (or equivalently equation (22)) is listed in Table $1, \varepsilon$ being defined by equation (21). The error increases with increasing fog formation levels, which might be expected, but remains within an acceptable magnitude for realistic conditions (the upper ones of Table 1).

For the second group of calculations $\left(t_{i}, c_{i}\right)$ is set equal to $\left(94.81^{\circ} \mathrm{C}, 0.75\right)$, and the bulk values $\left(t_{\mathrm{b}}, c_{\mathrm{b}}\right)$ equal to $\left(97.63^{\circ} \mathrm{C}, 0.875\right)$ and $\left(99.90^{\circ} \mathrm{C}, 0.995\right)$. All points are again situated on the saturation line of an

Table 1. Results of the numerical solution for $\left(t_{\mathrm{i}}, c_{\mathrm{i}}\right)-\left(20^{\circ} \mathrm{C}, 0.0144\right), \delta_{\mathrm{a}} / \delta_{\mathrm{r}}=\delta_{\mathrm{a}} / \delta_{r}=1$ for all cases

\begin{tabular}{lccccccc}
\hline & $L e_{\mathrm{v}}$ & $\Theta_{\mathrm{t}, \mathrm{r} 1} / \Theta_{,}$ & $\Theta_{c, \mathrm{f} \mathrm{f}} / \Theta_{c}$ & $\dot{M}_{\mathrm{f} 1}$ & $\dot{M}_{\mathrm{f} 1}$ & $q_{\mathrm{tot} . \mathrm{f} 1} / q_{\mathrm{tot}}$ & $|\varepsilon|$ \\
\hline$t_{\mathrm{b}}=30^{\circ} \mathrm{C}$ & 0.50 & 1.218 & 0.924 & 0.391 & 0.393 & 1.000 & 0.096 \\
$c_{\mathrm{b}}=0.0264$ & 0.75 & 1.192 & 0.901 & 0.350 & 0.352 & 1.000 & 0.120 \\
& 1.00 & 1.170 & 0.883 & 0.316 & 0.317 & 1.000 & 0.136 \\
& 1.25 & 1.153 & 0.868 & 0.288 & 0.289 & 1.000 & 0.148 \\
$t_{\mathrm{b}}=60^{\circ} \mathrm{C}$ & 0.50 & 1.418 & 0.791 & 2.050 & 2.091 & 1.002 & 0.736 \\
$c_{\mathrm{b}}=0.1318$ & 0.75 & 1.301 & 0.723 & 1.883 & 1.919 & 1.001 & 0.805 \\
& 1.00 & 1.180 & 0.671 & 1.731 & 1.762 & 1.001 & 0.819 \\
& 1.25 & 1.073 & 0.630 & 1.601 & 1.629 & 1.000 & 0.810 \\
\hline
\end{tabular}


Table 2. Results of the numerical solution for $\left(t_{i}, c_{i}\right)=\left(94.81^{\circ} \mathrm{C}, 0.75\right)$

\begin{tabular}{lcccccccc}
\hline & $L e_{\mathrm{v}}$ & $\Theta_{t, \mathrm{f} 1} / \Theta_{t}$ & $\Theta_{c, \mathrm{fl}} / \Theta_{c}$ & $\dot{M}_{\mathrm{f} 1}$ & $\dot{M}_{\mathrm{f} 1}$ & $\delta_{\mathrm{a}} / \delta_{c}$ & $q_{\mathrm{tot}, \mathrm{f} 1} / q_{\mathrm{tot}}$ & $H\left(t_{\mathrm{a}}\right)$ \\
\hline$t_{\mathrm{b}}=97.63^{\circ} \mathrm{C}$ & 0.80 & 1.019 & 0.999 & 0.031 & 0.026 & 0.37 & 1.000 & 0.77 \\
$c_{\mathrm{b}}=0.875$ & 0.90 & 1.062 & 0.999 & 0.121 & 0.121 & 1.00 & 1.000 & 0.84 \\
& 1.00 & 1.098 & 0.999 & 0.198 & 0.198 & 1.00 & 1.000 & 0.84 \\
& 1.10 & 1.129 & 0.999 & 0.261 & 0.261 & 1.00 & 1.001 & 0.84 \\
$t_{\mathrm{b}}=99.90^{\circ} \mathrm{C}$ & 0.80 & 1.000 & 1.000 & 0.000 & 0.000 & 0.00 & 1.000 & 0.71 \\
$c_{\mathrm{b}}=0.995$ & 0.90 & 1.080 & 0.999 & 0.356 & 0.346 & 0.14 & 1.000 & 0.82 \\
& 1.00 & 1.191 & 0.999 & 0.778 & 0.780 & 1.00 & 1.000 & 0.99 \\
& 1.10 & 1.298 & 0.998 & 0.132 & 1.135 & 1.00 & 1.000 & 0.99 \\
\hline
\end{tabular}

air-water vapour mixture. These temperatures and concentrations are relevant to condensers. The calculations are carried out for $L e_{\mathrm{v}}=0.8,0.9,1$ and 1.1 , the same latent to specific heat ratio, and equal thermal and diffusion film thicknesses. The values of $L e_{\mathrm{v}}$ are different from those of the previous set of calculations since an evaluation of equation (1) indicated that for all afore-mentioned condenser conditions and $L e_{\mathrm{v}}=0.5$ and 0.75 , fog is not formed at all. For these small $L e_{\mathrm{v}}$ values the convex curvc $G(t)$ is entirely situated in the superheated region. Thus, although the interface and bulk properties are both situated on the saturation line, fog is not formed. Consequently, the conventional correction factors of ref. [1] retain their validity for these cases.

In Table 2 the calculated correction factor ratios and dimensionless fog formation levels are listed for the cases considered. $\Lambda$ s for some cases the film is now partly or even entirely superheated, the dimensionless fog layer thickness $\delta_{\mathrm{a}} / \delta_{c}$ is also included in this table, $0 \leqslant \delta_{\mathrm{a}} / \delta_{c^{\prime}}=\delta_{\mathrm{a}} / \delta_{t} \leqslant 1$. In Fig. 1 the determined temperature and concentration profiles in the film, with $y$ as parameter, for $L e_{\mathrm{v}}=0.8$ and 0.9 are drawn as examples. For $L e_{\mathrm{v}}=0.8$ the curve $G(t)$ is situated in the superheated region, as correctly predicted by equation (1). According to this equation fog is formed for $L e_{\mathrm{v}}=0.9$. With equation (11) the border of the superheated region $\left(t_{\mathrm{a}}, c_{\mathrm{a}}\right)$ has been determined. In Fig. 1 the continuity of the first derivalive $\mathrm{d} c / \mathrm{d} t$ at the boundary between saturated and superheated zones is evident. In Table 2 or Fig. 1 it can be seen that for the examined situations the film can be entirely superheated, partly superheated and saturated, or entirely saturated. The correction factor ratios for heat and mass transfer differ most from unity, of course, when the entire film is saturated. For $L e_{\mathrm{v}} \geqslant 1$ the entire film is always saturated when the bulk is saturated. This feature of the film for $L e_{\mathrm{v}}=1$ was employed implicitly by Areî'yev and Averkiyev [17] and is explained in ref. [23]. In Table $2 H\left(t_{\mathrm{a}}\right)$ has been included, see equation (A4), with $t_{\mathrm{a}}=t_{\mathrm{i}}$ substituted for a superheated film and $t_{\mathrm{a}}=t_{\mathrm{b}}$ for an entirely saturated film. One can readily see that the maximum $H\left(t_{\mathrm{a}}\right)$ of the film is smaller than $L e_{\mathrm{v}}$ for all cases examined, thus $K>0$ is assumed. In ref. [23] it is deduced that $t_{\mathrm{a}}$ is always such that $H\left(t_{\mathrm{a}}\right)<L e_{\mathrm{v}}$ is fulfilled.

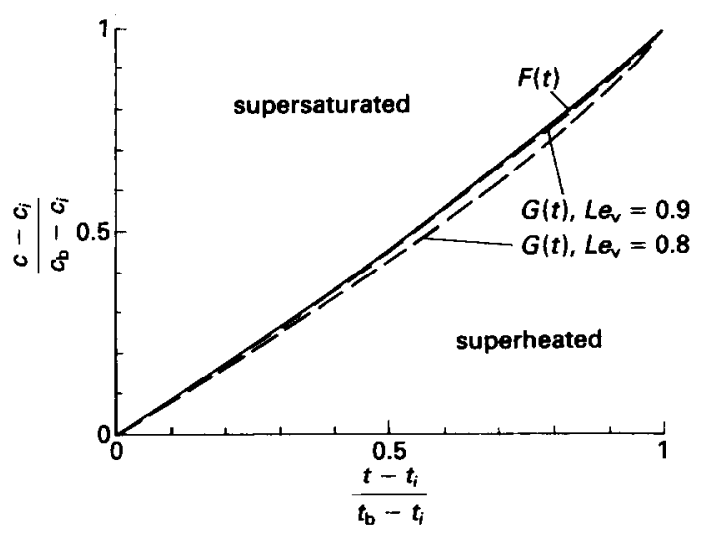

FlG. 1. Behaviour of vapour concentration and temperature in the film with respect to the saturation line, $\left(t_{\mathrm{i}}, c_{\mathrm{i}}\right)=$ $\left(94.81^{\circ} \mathrm{C}, 0.75\right)$ and $\left(t_{\mathrm{b}}, c_{\mathrm{b}}\right)=\left(99.90^{\circ} \mathrm{C}, 0.995\right)$.

A glance at the total transferred heat and the diffusion correction factor ratios shows that these are now both nearly unity, even for completely saturated films. This means that fog formation does not seriously affect the vapour diffusion and latent heat transfer in condensers. In condensers, however, the main part of transferred heat is latent heat; Sparrow et al. [26], for example, demonstrated that the sensible heat transfer is negligibly small because the temperature difference between wall and bulk is very small. As the diffusional mass transfer is hardly altered by fog formation, not only will the overall heat transfer in a condenser be the same in the case of fog formation, but also the dominant latent mode of heat transfer will remain the same. Or in other words, for condenser calculations the conventional film model will predict heat and mass transfer rates sufficiently accurately, with or without fog formation.

The relatively unimportant effect of fog formation in condensers is once more illustrated by the small amount of fog formed, see $\dot{M}_{\mathrm{f}}$ in Table 2 . One must be aware when the actual amount of fog formed is considered, that the temperature differences $\left(t_{\mathrm{b}}-t_{\mathrm{i}}\right)$ pertaining to Table 1 are much larger than those pertaining to Table 2. As the maximum introduced error $\varepsilon$, which is correlated with $K$ and $\dot{m}_{f}$, is also much smaller for the physical situations studied here, it has not been listed in Table 2 . 
In the analysis of the previous section no attention has been paid to the film momentum equation in the case of fog formation, nor has there been derived a correction factor for friction in a fogged film. The correction for suction or injection is only of importance when the vapour mass fractions are large. The calculation of diffusional mass transfer in the case of fog formation has shown that the diffusion profile in the film is significantly altered only for small vapour mass fractions. But for small vapour mass fractions the mass flux as such is small and thus the friction correction factor close to unity. For large vapour fractions the correction becomes important, but for this case the concentration profile, and pertaining mass flux, is nearly unchanged by fogging. Accordingly, the author confines himself by suggesting a substitution of the mass flux in the conventional correction factor will be a good approximation of the true friction correction factor. The substituted mass flux may be calculated by either the classical or the fog film model.

\section{ASYMPTOTIC APPROXIMATION SOLUTION}

In the previous section the coupled energy and diffusion equation (14) of the fog layer has been solved numerically. To this end, a standard shooting method was employed to solve the boundary value problem. This numerical method consists of a combined integration and iteration routine to find a solution which satisfies both boundary conditions of $t$ at $y=0$ and $\delta_{\mathrm{a}}$. In the context of an operating heat exchanger $t_{\mathrm{i}}$ and $c_{\mathrm{i}}=F\left(t_{\mathrm{i}}\right)$ have to be calculated iteratively, since the interface temperature and concentration in an evaporator or condenser have to obey a local energy balance, and are not known a priori. The coupled application of an iteration for $t_{\mathrm{i}}$, and a shooting method to solve equation (14) for each cycle of this iteration, yields long computation times. The derivation of an asymptotic approximate solution of equation (14) is therefore desirable and this is presented in this section.

In order to derive an approximate solution of equation (14), an assessment of the order of magnitude of the diverse terms is first carried out. For small vapour mass fractions the first term on the left-hand side of equation (14) is of about the same magnitude as the term on the right-hand side. The latter is of importance because, even for small $c$, this term is large by virtue of the presence of the latent specific heat ratio. This becomes evident when the typical values appearing in Table 1 are considered and one realizes that $L e_{v}$ is of the order of unity and $H_{1 \mathrm{a}} / c_{p, \mathrm{v}}$ is of the order of $120-1200 \mathrm{~K}$ for most vapours. The second and nonlinear term on the left-hand side is very small when compared with the two aforesaid terms of equation (14). For large vapour mass fractions (see Table 2 for typical values of $c$ and $t$ ) the term on the right-hand side completely dominates both of the other terms in equation (14). Thus again, the non-linear term plays no role of importance.
The considerations of small and large vapour concentrations yield the relative unimportance of the second and non-linear term on the left-hand side of equation (14). Evaluating the equation without this non-linear term indeed yields a promising agreement between the reduced solution and the complete numerical solution of equation (14). Yet, a much better agreement is obtained by assessing the contribution of this term to the complete solution.

The non-linear term only becomes of some importance for large vapour fractions, when it exceeds the other term on the left-hand side of equation (14). But again it must be stressed that under these circumstances both terms are small in comparison with the term on the right-hand side of the equation. Mathematically, then, for large vapour fractions the solution of

$$
\frac{\mathrm{d}^{2} \ln (1-c)}{\mathrm{d} y^{2}}=0
$$

accurately approximates the complete solution of equation (14). Integration of equation (32) and application of the boundary conditions at the interface and equation (4) yields

$$
c(y)=1-\left(1-c_{\mathrm{i}}\right) \exp \left\{\frac{y}{\delta_{\mathrm{a}}} \ln \left(\frac{1-c_{\mathrm{a}}}{1-c_{\mathrm{i}}}\right)\right\} \quad\left(0 \leqslant y \leqslant \delta_{\mathrm{a}}\right) .
$$

This solution for the saturated layer, combined with solution (6) for the superheated layer, corresponds exactly to the undisturbed diffusion profile of a film without fog formation [1]. This is the reason that for large vapour fractions the conventional diffusional correction factor without fog almost coincides with that of the film model with fog, as confirmed by the numerical results listed in Table 2 .

To obtain a higher order approximate solution of equation (14), the zero-order solution (33) is substituted in the non-linear term of equation (14)

$L e_{\mathrm{v}} \frac{\mathrm{d}^{2} t}{\mathrm{~d} y^{2}}-\frac{1}{\delta_{\mathrm{a}}} \ln \left(\frac{1-c_{\mathrm{a}}}{1-c_{\mathrm{i}}}\right) \frac{\mathrm{d} t}{\mathrm{~d} y}=\frac{H_{\mathrm{lat}}}{c_{p, \mathrm{v}}} \frac{\mathrm{d}^{2} \ln (1-c)}{\mathrm{d} y^{2}}$.

The asymptotic solution (33) has been substituted in the non-linear term since only for large vapour fractions this term becomes of some importance. For small vapour fractions this term is still dominated by both of the other terms appearing in equation (14) or (34). Equation (34) is integrated twice with respect to $y$

$$
\begin{aligned}
& L e_{\mathrm{v}} t(y)-\frac{1}{\delta_{\mathrm{a}}} \ln \left(\frac{1-c_{\mathrm{a}}}{1-c_{\mathrm{i}}}\right) \int_{y=0}^{y} t(y) \mathrm{d} y \\
& =\frac{H_{\mathrm{at}}}{c_{p, \mathrm{v}}} \ln (1-c(y))+K_{1} y+K_{2} \quad\left(0 \leqslant y \leqslant \delta_{\mathrm{a}}\right) .
\end{aligned}
$$

Applying the boundary conditions at the interface and equations (3) and (4) yields the integration constants 


$$
\begin{aligned}
K_{1}=\frac{L e_{\mathrm{v}}\left(t_{\mathrm{a}}-t_{\mathrm{i}}\right)}{\delta_{\mathrm{a}}}-\frac{1}{\delta_{\mathrm{a}}} & \ln \left(\frac{1-c_{\mathrm{a}}}{1-c_{\mathrm{i}}}\right) \\
& \times\left(\frac{H_{\mathrm{lat}}}{c_{p, \mathrm{v}}}+\frac{1}{\delta_{\mathrm{a}}} \int_{y=0}^{\delta_{\mathrm{a}}} t \mathrm{~d} y\right)
\end{aligned}
$$

and

$$
K_{2}=L e_{\mathrm{v}} t_{\mathrm{i}}-\stackrel{H_{\text {lat }}}{--} \ln \left(1-c_{\mathrm{i}}\right)
$$

The integral appearing in equation (36) is assessed with the help of the zero-order solution (33). This
Substitution of equation (39) into equation (36) now yields

$$
\begin{aligned}
K_{1}=\left(L e_{\mathrm{v}}-1\right) & \frac{\left(t_{\mathrm{a}}-t_{\mathrm{i}}\right)}{\delta_{\mathrm{a}}}-\frac{1}{\delta_{\mathrm{a}}} \ln \left(\frac{1-c_{\mathrm{a}}}{1-c_{\mathrm{i}}}\right) \\
& \times\left(\frac{H_{\mathrm{lat}}}{c_{p, \mathrm{v}}}+\frac{t_{\mathrm{a}}\left(1-c_{1}\right)-t_{\mathrm{i}}\left(1-c_{\mathrm{a}}\right)}{c_{\mathrm{a}}-c_{\mathrm{i}}}\right) .
\end{aligned}
$$

A complete approximate solution (35), combined with equations (37) and (40), of equation (14) has now been realized. The dimensionless fog layer thickness is obtained by combining equations (5), (7), (9), (22), (35) and (40)

$$
\frac{\delta_{c}}{\delta_{\mathrm{a}}}=1+\frac{1}{L e_{\mathrm{v}}}\left[\frac{\left(t_{\mathrm{b}}-t_{\mathrm{a}}\right) \ln \left(\frac{1-c_{\mathrm{b}}}{1-c_{\mathrm{a}}}\right)}{\exp \left\{\frac{1}{L e_{\mathrm{v}}} \ln \left(\frac{1-c_{\mathrm{i}}}{1-c_{\mathrm{a}}}\right)+\frac{\delta_{t}}{L e_{\mathrm{v}} \delta_{c}} \ln \left(\frac{1-c_{\mathrm{b}}}{1-c_{\mathrm{i}}}\right)\right\}-1}\right]
$$

$$
\times\left[\frac{\left(L e_{\mathrm{v}}+\left.\frac{H_{\mathrm{lat}}}{c_{p, v}} \frac{1}{1-c_{\mathrm{a}}} \frac{\mathrm{d} F}{\mathrm{~d} t}\right|_{t_{\mathrm{a}}}\right)}{\left(L e_{\mathrm{v}}-1\right)\left(t_{\mathrm{a}}-t_{\mathrm{i}}\right)-\ln \left(\frac{1-c_{\mathrm{a}}}{1-c_{\mathrm{i}}}\right)\left(\frac{H_{\mathrm{lat}}}{c_{p, v}}-t_{\mathrm{a}}+\frac{t_{\mathrm{a}}\left(1-c_{\mathrm{i}}\right)-t_{\mathrm{i}}\left(1-c_{\mathrm{a}}\right)}{c_{\mathrm{a}}-c_{\mathrm{i}}}\right)}\right] .
$$

equation constitutes an expression for $c$ as a function of $y$, while $t$ as a function of $y$ is needed to solve the integral. In the fog layer, however, $c$ is determined by the saturation function (5) as a function of $t$, and conversely, $t$ is a known function of $c$. However, in general this relation permits no further analytic treatment of the integral. As a compromise, therefore, the saturation line in the saturated region is now roughly approximated as a straight line between
The thermal correction factor follows from equations (15) and (24)

$$
\Theta_{t, \mathrm{f}}=\frac{\left.\delta_{t} \frac{\mathrm{d} t}{\mathrm{~d} y}\right|_{y=0}}{\left(t_{\mathrm{b}}-t_{\mathrm{i}}\right)}
$$

The first derivative of $t$ with respect to $y$ at the wall, according to the approximate solution, is determined with the help of equations (5), (35) and (40)

$$
\left.\delta_{t} \frac{\mathrm{d} t}{\mathrm{~d} y}\right|_{y=0}=\frac{\delta_{t}}{\delta_{\mathrm{a}}} \cdot \frac{\left(L e_{\mathrm{v}}-1\right)\left(t_{\mathrm{a}}-t_{\mathrm{i}}\right)-\ln \left(\frac{1-c_{\mathrm{a}}}{1-c_{\mathrm{i}}}\right)\left(\frac{H_{\mathrm{lat}}}{c_{p, \mathrm{v}}}-t_{\mathrm{i}}+\frac{t_{\mathrm{a}}\left(1-c_{\mathrm{i}}\right)-t_{\mathrm{i}}\left(1-c_{\mathrm{a}}\right)}{c_{\mathrm{a}}-c_{\mathrm{i}}}\right)}{L e_{\mathrm{v}}+\left.\frac{H_{\mathrm{lat}}}{c_{p, \mathrm{v}}} \frac{1}{1-c_{\mathrm{i}}} \frac{\mathrm{d} F}{\mathrm{~d} t}\right|_{t_{\mathrm{i}}}}
$$

$$
\begin{aligned}
& \left(t_{\mathrm{i}}, c_{\mathrm{i}}\right) \text { and }\left(t_{\mathrm{a}}, c_{\mathrm{a}}\right) \\
& \quad t=F^{\mathrm{inv}}(c) \cong \frac{c-c_{\mathrm{i}}}{c_{\mathrm{a}}-c_{\mathrm{i}}}\left(t_{\mathrm{a}}-t_{\mathrm{i}}\right)+t_{\mathrm{i}} \quad\left(c_{\mathrm{i}} \leqslant c \leqslant c_{\mathrm{a}}\right)
\end{aligned}
$$

In equation (38) for $c$ the zero-order solution (33) is again substituted and the integral in equation (36) is solved analytically as follows :

$\frac{1}{\delta_{\mathrm{a}}} \int_{y=0}^{\delta_{\mathrm{a}}} t \mathrm{~d} y=\frac{t_{\mathrm{a}}\left(1-c_{\mathrm{i}}\right)-t_{\mathrm{i}}\left(1-c_{\mathrm{a}}\right)}{c_{\mathrm{a}}-c_{\mathrm{i}}}+\frac{t_{\mathrm{a}}-t_{\mathrm{i}}}{\ln \left(\frac{1-c_{\mathrm{a}}}{1-c_{\mathrm{i}}}\right)}$.
The dimensionless fog layer thickness in this equation is given by equation (41). The diffusional correction factor pertaining to the approximate solution can easily be obtained by combining equations (27) and (42)

$$
\Theta_{c, \mathrm{f}}=\frac{\left.\left.\delta_{c} \frac{\mathrm{d} F}{\mathrm{~d} t}\right|_{t_{\mathrm{i}}} \frac{\mathrm{d} t}{\mathrm{~d} y}\right|_{y=0}}{\left(c_{\mathrm{b}}-c_{\mathrm{j}}\right)} .
$$

The amount of fog formed is determined by equations (13) and (28)

$\dot{m}_{\mathrm{f}}=\rho \mathbb{D}\left(\left.\frac{\mathrm{d} \ln (1-c)}{\mathrm{d} y}\right|_{y=0}-\left.\frac{\mathrm{d} \ln (1-c)}{\mathrm{d} y}\right|_{y=\delta_{\mathrm{a}}}\right)$. 
This equation, combined with equations (35) and (36), is written as

$$
\begin{aligned}
\dot{m}_{\mathrm{f} 2}=\frac{k}{H_{\mathrm{lat}} \delta_{t}}\left(\left.\delta_{t} \frac{\mathrm{d} t}{\mathrm{~d} y}\right|_{y=0}-\left.\delta_{t} \frac{\mathrm{d} t}{\mathrm{~d} y}\right|_{y=\delta_{\mathrm{a}}}\right. \\
\left.+\frac{\delta_{t}}{\delta_{\mathrm{a}}} \frac{\left(t_{\mathrm{a}}-t_{\mathrm{i}}\right)}{L e_{\mathrm{v}}} \ln \left(\frac{1-c_{\mathrm{a}}}{1-c_{\mathrm{i}}}\right)\right) .
\end{aligned}
$$

The first derivative of $t$ in $y=0$ in equation (46) follows from equation (43), the first derivative in $y=\delta_{\mathrm{a}}$ is calculated by combining equations (5), (35) and (40) and 2 , respectively. To determine the boundary of saturation $\left(t_{\mathrm{a}}, c_{\mathrm{a}}\right)$, equation (11) has again been employed, again, of course, yielding identical $\left(t_{\mathrm{a}}, c_{\mathrm{a}}\right)$ and $H\left(t_{\mathrm{a}}\right)$ for all cases examined.

A comparison of all values listed in Tables 1-4, shows the maximum discrepancy between numerical and approximate solutions is of about a few per

$$
\left.\delta_{t} \frac{\mathrm{d} t}{\mathrm{~d} y}\right|_{y=\delta_{\mathrm{a}}}=\frac{\delta_{t}}{\delta_{\mathrm{a}}} \cdot \frac{\left(I e_{\mathrm{v}}-1\right)\left(t_{\mathrm{a}}-t_{\mathrm{i}}\right)-\ln \left(\frac{1-c_{\mathrm{a}}}{1-c_{\mathrm{i}}}\right)\left(\frac{H_{\mathrm{lat}}}{c_{p, \mathrm{v}}}-t_{\mathrm{a}}+\frac{t_{\mathrm{a}}\left(1-c_{\mathrm{i}}\right)-t_{\mathrm{j}}\left(1-c_{\mathrm{a}}\right)}{c_{\mathrm{a}}-c_{\mathrm{i}}}\right)}{L e_{\mathrm{v}}+\left.\frac{H_{\mathrm{lat}}}{c_{p, \mathrm{v}}} \frac{1}{1-c_{\mathrm{a}}} \frac{\mathrm{d} F}{\mathrm{~d} t}\right|_{t_{\mathrm{a}}}} .
$$

The dimensionless fog layer thickness appearing in equations (43), (46) and (47) follows from equation (41).

\section{RESULTS OF ASYMPTOTIC SOLUTION}

In this section similar calculations to those presented in Section 3 are carried out to compare the predictions of the asymptotic approximate solution with those of the complete numerical solution. In Tables 3 and 4 the results of these calculations are listed which correspond with the computational results of the complete model, as listed in Tables 1 mille. Even for the largest difference between $\left(t_{i}, c_{\mathrm{j}}\right)$ and $\left(t_{\mathrm{b}}, c_{\mathrm{b}}\right)$, the agreement is still very good. This large difference belongs to unrealistically large sensible and latent heat fluxes from gas to wall. It will therefore not be found in ordinary heat exchangers or condensers, it has only been selected to create some deviation between the numerical and approximate solutions.

One can furthermore conclude from Tables 1 and 3 that the error decreases with increasing $L e_{\mathrm{y}}$. For larger $L e_{\mathrm{v}}$ the first term on the left-hand side of equation (14) gains importance and dominates more the second term, resulting in a smaller deviation. For small vapour fractions it is namely important for the

Table 3. Results of the approximate solution for $\left(t_{\mathrm{i}}, c_{\mathrm{i}}\right)=\left(20^{\circ} \mathrm{C}, 0.0144\right), \delta_{\mathrm{a}} / \delta_{c}=\delta_{\mathrm{a}} / \delta_{t}=1$ for all cases

\begin{tabular}{lccccccc}
\hline & $L e_{\mathrm{v}}$ & $\Theta_{\mathrm{l}, \mathrm{f} 2} / \Theta_{t}$ & $\Theta_{c, \mathrm{f} 2} / \Theta_{c}$ & $\dot{M}_{\mathrm{f} 2}$ & $\dot{\bar{M}}_{\mathrm{f} 2}$ & $q_{\mathrm{tot}, \mathrm{f} 2} / q_{\mathrm{tot}}$ & $|\varepsilon|$ \\
$t_{\mathrm{b}}=30^{\circ} \mathrm{C}$ & 0.50 & 1.218 & 0.924 & 0.391 & 0.393 & 1.000 & 0.096 \\
$c_{\mathrm{b}}=0.0264$ & 0.75 & 1.192 & 0.901 & 0.350 & 0.352 & 1.000 & 0.120 \\
& 1.00 & 1.170 & 0.883 & 0.316 & 0.317 & 1.000 & 0.136 \\
& 1.25 & 1.153 & 0.868 & 0.288 & 0.289 & 1.000 & 0.148 \\
$t_{\mathrm{b}}=60^{\circ} \mathrm{C}$ & 0.50 & 2.411 & 0.789 & 2.035 & 2.068 & 0.999 & 0.736 \\
$c_{\mathrm{b}}=0.1318$ & 0.75 & 2.297 & 0.721 & 1.871 & 1.915 & 0.999 & 0.802 \\
& 1.00 & 2.177 & 0.670 & 1.722 & 1.760 & 1.000 & 0.817 \\
& 1.25 & 2.071 & 0.629 & 1.594 & 1.627 & 1.000 & 0.809
\end{tabular}

Table 4. Results of the approximate solution for $\left(t_{i}, c_{\mathrm{i}}\right)=\left(94.81^{\circ} \mathrm{C}, 0.75\right)$

\begin{tabular}{lcccccccc}
\hline & $L e_{\mathrm{v}}$ & $\Theta_{\mathrm{t}, \mathrm{f} 2} / \Theta_{r}$ & $\Theta_{\mathrm{c}, \mathrm{f} 2} / \Theta_{c}$ & $\dot{M}_{\mathrm{f} 2}$ & $\overline{\dot{M}}_{\mathrm{f} 2}$ & $\delta_{\mathrm{a}} / \delta_{c}$ & $q_{\text {tot } \mathrm{f} 2} / q_{\mathrm{tol}}$ & $H\left(t_{\mathrm{a}}\right)$ \\
\hline$t_{\mathrm{b}}=97.63^{\circ} \mathrm{C}$ & 0.80 & 1.019 & 0.999 & 0.031 & 0.026 & 0.37 & 1.000 & 0.77 \\
$c_{\mathrm{b}}=0.875$ & 0.90 & 1.062 & 0.999 & 0.121 & 0.121 & 1.00 & 1.000 & 0.84 \\
& 1.00 & 1.098 & 0.999 & 0.198 & 0.198 & 1.00 & 1.000 & 0.84 \\
& 1.10 & 1.129 & 0.999 & 0.261 & 0.261 & 1.00 & 1.000 & 0.84 \\
$t_{\mathrm{b}}=99.90^{\circ} \mathrm{C}$ & 0.80 & 1.000 & 1.000 & 0.000 & 0.000 & 0.00 & 1.000 & 0.71 \\
$c_{\mathrm{b}}=0.995$ & 0.90 & 1.080 & 0.999 & 0.356 & 0.346 & 0.14 & 1.000 & 0.82 \\
& 1.00 & 1.191 & 0.999 & 0.777 & 0.780 & 1.00 & 1.000 & 0.99 \\
& 1.10 & 1.298 & 0.998 & 0.130 & 1.135 & 1.00 & 1.000 & 0.99 \\
\hline
\end{tabular}


approximation to be accurate that both $L e_{\mathrm{v}}$ and $H_{\mathrm{lat}} / c_{p, \mathrm{v}}$ are large. For large vapour mass fractions however, the error slightly increases with larger $L e_{\mathrm{v}}$, see Tables 2 and 4 . For these physical situations it is important that $H_{\mathrm{iat}} / c_{p, \mathrm{v}}$ is large and consequently the right-hand side of equation (14) dominates both terms on the left-hand side.

The approximation is based on the fact that $H_{1 a t} / c_{p, v}$ is large. For water vapour this ratio is close to $1200 \mathrm{~K}$, but for a lot of other vapours it is a factor of 10 smaller. A repetition of all calculations, with $H_{\mathrm{lat}} / c_{p, \mathrm{v}}=120 \mathrm{~K}$ and all other values unchanged, indi cated however that the approximation solution is still correct within a few per cent. Since this error is quite acceptable, the approximate solution is not only applicable to water vapour, but to most other vapours as well.

In Tables 1-4 only results pertinent to conditions found in air-conditioning devices and condensers have been listed. Computations carried out for intermediate vapour fractions and temperatures, for instance found in exhaust gases from dryers, indicate that the agreement is of the same high level as in the cases studied in detail here. Furthermore, since the temperature as a function of $y$ in the fog layer has been found to be similar for evaporation and condensation, the approximation is applicable to evaporation processes as well.

\section{APPLICATION OF THE FOG FILM MODEL TO CHANNEL FLOW}

In preceding sections the conditions have been discussed under which fog formation in the film occurs and modified correction factors derived. In this section the use of this extended film model is demonstrated. This model includes the possibility that the bulk properties move to enter the supersaturated region and that, as a result, bulk fog is created. Similar to the conventional film model, here the bulk values $t_{\mathrm{b}}$ and $c_{\mathrm{b}}$ are taken to be sufficiently approximated by the mixed mean values of these quantities in a crosssection. A flow chart, drawn in Fig. 2, illustrates the procedure followed.

\subsection{Determination of interface conditions $\left(t_{\mathrm{i}}, c_{\mathrm{i}}\right)$}

In evaporators or condensers the interface temperature $t_{\mathrm{i}}$ and associated vapour mass fraction $c_{\mathrm{i}}$ $\left(=F\left(t_{i}\right)\right)$ are determined by a local energy balance. The net latent and sensible heat flux from or to an interface must be zero, the fluxes on the gas side being given by the conventional film model corrections for heat and

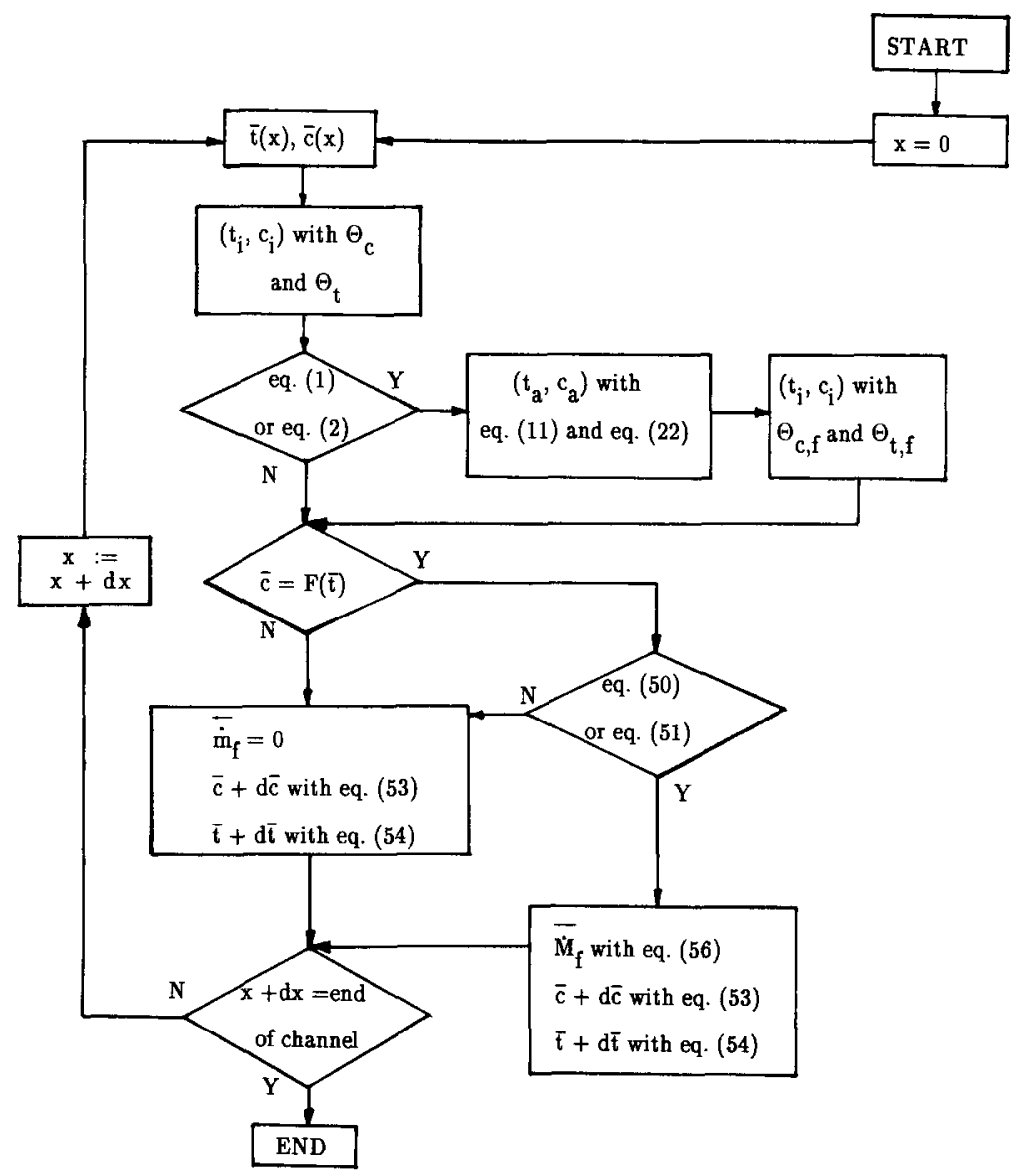

FIG. 2. Flow chart of the applied fog film model. 
mass transfer. Once $t_{\mathrm{i}}$ has been obtained, equation (1) or equation (2) for suction or injection, respectively, is employed to determine whether the vapour concentration/temperature line $G(t)$ is located in the supersaturated region. These conventional film model expressions are based on the assumption of no intersection of this relation with the saturation line. If this proves indeed to be the case, the $t_{1}$ and fluxes calculated, according to equation (1) or (2), are correct and the amount of fog formed in the film is equal to zero.

If, on the other hand, an intersection between equation $G(t)$ and the saturation line is detected, an alternative procedure has to be followed. First, the temperature and vapour concentration $\left(t_{\mathrm{a}}, c_{\mathrm{a}}\right)$ on the boundary of the saturated and superheated region is determined numerically with the help of equations (11) and (22). By employing a local energy balance, $t_{\mathrm{i}}$ is then re-determined. But during this iterative procedure now the fog correction factors $\Theta_{c, \mathrm{f}}$ and $\Theta_{t, \mathrm{f}}$ are utilized to predict the transfer on the gas side.

\subsection{Incremental mass and energy balances}

As long as the bulk (or mean mixed flow) is not saturated (that is to say, $(\bar{t}, \bar{c})$ is located in the superheated region) the mixture's incremental temperature and vapour concentration changes are still governed by the equations derived in ref. [1]. Note that it is possible for fog to be predicted in the film without the bulk flow being saturated. Physically this means that if the flow in a cross-section is mixed, fog present near the wall would evaporate on contact with the superheated core flow.

The slope of the $(\bar{t}, \bar{c})$ path in the case of fog formation in the film is now obtained by combining the global mass and energy balances of ref. [1] ('equation (36)' and 'equation (38)', respectively), applying equations (25), (27) and (42), and $g_{m}=\rho \mathbb{D} / \delta_{c}$ and $h_{\mathrm{g}}=k / \delta_{\text {, }}$

$$
\frac{\mathrm{d} \bar{c}}{\mathrm{~d} \bar{t}}=\frac{\mathrm{d} \bar{G}}{\mathrm{~d} \bar{t}}=\frac{1}{L e} \frac{-\left.\frac{1-\bar{c}}{1-c_{\mathrm{i}}} \frac{\mathrm{d} F}{\mathrm{~d} t}\right|_{t_{\mathrm{i}}}}{\left.\frac{1}{L e_{\mathrm{v}}} \frac{\bar{t}-t_{\mathrm{i}}}{\mathrm{I}-c_{\mathrm{i}}} \frac{\mathrm{d} F}{\mathrm{~d} t}\right|_{t_{\mathrm{i}}}-1} .
$$

In ref. [1] the path of the bulk properties has been deduced in the case that the film is superheated. In the case fog is formed in the film a similar result is now obtained by separating the variables $\bar{c}$ and $\bar{t}$ of equation (48) and integrating

$$
\begin{aligned}
\bar{c}=\bar{G}(\bar{t}) & =1-(1-\bar{c}(x=0)) \\
\times & {\left[\frac{\left.\left(\bar{t}-t_{\mathrm{i}}\right) \frac{\mathrm{d} F}{\mathrm{~d} t}\right|_{t_{\mathrm{i}}}-L e_{\mathrm{v}}\left(1-c_{\mathrm{i}}\right)}{\left.\left(\bar{t}(x=0)-t_{\mathrm{i}}\right) \frac{\mathrm{d} F}{\mathrm{~d} t}\right|_{t_{\mathrm{i}}}-L e_{\mathrm{v}}\left(1-c_{\mathrm{i}}\right)}\right]^{L e_{\mathrm{v}} / L} }
\end{aligned}
$$

whereby the vapour fraction and temperature at an arbitrary location, $x=0$, has been applied as bound- ary condition. The path $\bar{G}(\bar{t})$ is used to detect the intersection of the path of the bulk properties and the saturation line. The path $\bar{G}(\bar{t})$ hold up to the point when the bulk flow is saturated $(\bar{c}=F(\bar{t})$ and the path of the mixture's bulk properties is directed into the supersaturated region (see Fig. 3).

For condensation the condition for entry of the bulk into the supersaturated region then corresponds mathematically to

$$
\frac{\mathrm{d} \bar{G}}{\mathrm{~d} \bar{t}}<\left.\frac{\mathrm{d} F}{\mathrm{~d} t}\right|_{i}
$$

and for evaporation

$$
\frac{\mathrm{d} \bar{G}}{\mathrm{~d} \bar{t}}>\left.\frac{\mathrm{d} F}{\mathrm{~d} t}\right|_{\bar{t}}
$$

The incremental mass balance in the case of such a saturated bulk flow (i.e. one which would be supersaturated and therefore fogged after mixing of a crosssection) flowing through a channel reads

$$
\frac{\mathrm{d}(\rho \bar{u})}{\mathrm{d} x}=-\frac{4}{D_{\mathrm{h}}}\left(g_{m} \Theta_{c} \cdot \frac{\bar{c}-c_{\mathrm{i}}}{1-c_{\mathrm{i}}}+\overline{\dot{m}}_{\mathrm{f}}\right) .
$$

Neglecting the fraction of fog droplets, for a binary mixture the channel mass flux $(\rho \bar{u})(x)$ can again be expressed in terms of the vapour concentration by

$$
\frac{\mathrm{d} \bar{c}}{\mathrm{~d} x}=\frac{-4 g_{m}}{D_{\mathrm{h}}(\rho \bar{u})(x=0)}\left(\Theta_{c} \frac{\bar{c}-c_{\mathrm{i}}}{1-c_{\mathrm{i}}}+\frac{\bar{m}_{\mathrm{f}}}{g_{m}}\right) \frac{(1-\bar{c})^{2}}{(1-\bar{c}(x=0))}
$$

The differential energy equation for the supersaturated bulk flow becomes

$$
\begin{array}{r}
\frac{\mathrm{d} \bar{t}}{\mathrm{~d} x}=\frac{-4 h_{\mathrm{g}}}{c_{p} D_{\mathrm{h}}(\rho \bar{u})(x-0)}\left(\Theta_{t}-\frac{g_{m} c_{p, \mathrm{v}}}{h_{\mathrm{g}}} \Theta_{c} \frac{\bar{c}-c_{\mathrm{i}}}{1-c_{\mathrm{i}}}\right. \\
\left.-\frac{H_{\mathrm{lat}} \overline{\dot{m}}_{\mathrm{f}}}{h_{\mathrm{g}}\left(\bar{t}-t_{\mathrm{j}}\right)}\right)\left(\bar{t}-t_{\mathrm{i}}\right) \frac{(1-\bar{c})}{(1-\bar{c}(x=0))}
\end{array}
$$

As the fraction of droplets is very small, it is not expected to alter the mixture's physical properties significantly.

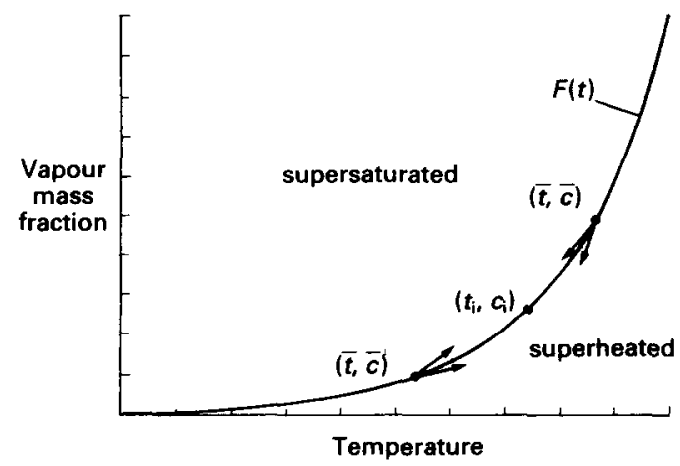

Fig. 3. Path of the mixture's bulk properties $(\bar{l}, \vec{c})$. 
In the energy equation the bulk fog created appears as a heat source, and in the gas mass conservation relation as a sink of matter. This bulk fog weakens the temperature drop and increases the fall in vapour fraction in situations with wall condensation. For wall evaporation, the fog formed increases the temperature rise and reduces the vapour fraction increment in a channel. The amount of fog in the bulk gas flow is such that the mixture's bulk properties $(\bar{t}, \bar{c})$ follow the saturation line. Mathematically the effective amount of fog is therefore calculated by requiring that

$$
\frac{\mathrm{d} \bar{G}}{\mathrm{~d} \bar{t}}=\frac{\mathrm{d} F}{\mathrm{~d} t} \mid \bar{i}
$$

With the help of $g_{m}=(S h \rho \mathbb{D}) / D_{\mathrm{h}}$ and $h_{\mathrm{g}}=(N u k) / D_{\mathrm{h}}$ and equations (30) and (53)-(55), the corresponding dimensionless amount of bulk fog in the channel can be determined as

$$
\bar{M}_{\mathrm{f}}=\frac{\left.\Theta_{t} \frac{\mathrm{d} F}{\mathrm{~d} t}\right|_{\bar{t}}-\frac{S h}{N u} \Theta_{c} \frac{\bar{c}-c_{\mathrm{i}}}{1-c_{\mathrm{i}}}\left(\left.\frac{1}{L e_{\mathrm{v}}} \frac{\mathrm{d} F}{\mathrm{~d} t}\right|_{\bar{i}}+\frac{1}{L e} \frac{1-\bar{c}}{\bar{t}-t_{\mathrm{i}}}\right)}{\left.\frac{\mathrm{d} F}{\mathrm{~d} t}\right|_{\bar{t}}+(1-\bar{c}) \frac{L e_{\mathrm{v}}}{L e} \frac{c_{p, \mathrm{v}}}{H_{\mathrm{lat}}}} .
$$

For a mixture with a (partly) saturated film the fog film model correction factors $\Theta_{t, \mathrm{f}}$ and $\Theta_{\text {c.f }}$, instead of $\Theta$, and $\Theta_{\text {c }}$, respectively, should be used in equations (53), (54) and (56). In this case the entering of the bulk properties into the supersaturated region is examined with equations (48)-(51).

In Tables $1-4$ the bulk fog formation according to equation (56) has been included with the Lewis number in $\bar{G}(\bar{t})$ and equation (56) chosen as unity and the equality $S h=N u$ substituted. The amount of fog formed in the film is smaller than, but close to, the bulk fog for all cases examined where the entire film was saturated $\left(\delta_{\mathrm{a}}=\delta_{c}=\delta_{t}\right)$.

On the other hand, the fog formed in the film is larger than the bulk fog when the film is partly superheated. This result would in fact be expected: the smaller the saturated part of the film is, the closer the correction factors approximate the conventional correction factors. For $L e=1$ the bulk properties $(\bar{t}, \bar{c})$, according to the conventional film model, are directed along $\bar{G}(t)$, which coincides with $G(t)$, see ref. [1]. This implies when a larger part of the film is situated in the superheated region, $(\bar{t}, \bar{c})$ is less directed into the saturated region and more directed along $G(t)$. This phenomenon becomes more pronounced when a larger part of the film is superheated, which is indeed confirmed by Tables 2 and 4 . It is interesting to observe that in such cases fog is present in a part of the film near the wall and in the bulk, both regions separated by a superheated film part. Furthermore, for an entirely superheated film, e.g. see Fig. 1 for $G(t)$ pertaining to $L e_{\mathrm{v}}=0.8$, the mixture follows this curve. This means that the bulk remains entirely within the superheated region while flowing through a channel : $\bar{G}(\bar{t})$ ('equation (51)' from ref. [1]) and equation (50) then predict no entering of the bulk properties into the supersaturated region and hence bulk fog is not formed either.

\section{CONCLUSIONS}

The conventional film model issues from heat, mass and momentum transfer in a film next to a wall. In this paper it has been demonstrated with slope conditions (1) and (2) for wall condensation and wall evaporation, respectively, that in a binary mixture a part of or the entire film is supersaturated. On the basis of the saturation condition the existence and magnitude of the fogging film region have been determined and calculated.

The solution of the governing non-linear basic equation of diffusion and energy in the fog layer has been found both numerically and approximately with an asymptotic analysis. Evaluating the heat and mass transfer rates proved the large influence of fog formation. In particular for small vapour fractions, the effect of fog formation on the contributions of latent and sensible heat transfer is significant, as well as the amount of fog produced. On the other hand, the mass transfer in a mixture with large vapour mass fractions, diffusional latent heat transfer is the dominant mode in a condenser or evaporator, is hardly affected by fog formation. The total amount of transferred heat is nearly the same as for a film without fog formation for all considered physical situations.

For large vapour fractions the temperature and vapour fraction in the film, correlated by $G(t)$, can be situated in the superheated region, even when the bulk is saturated. This is due to the fact that for large vapour fractions and $L e_{\mathrm{v}}<1$ the curvature of $G(t)$ is such that it lies entirely in the superheated region and consequently, the classical film model remains valid. The major role of $L e_{v}$ is once more emphasized when $K$, which should be positive in the fog layer, is considered. This condition is fulfilled for $L e_{\mathrm{v}} \geqslant 1$, but not guaranteed for $L e_{\mathrm{v}}<1$. The computational examples in this paper disclosed however that $K>0$ in all fog layers considered.

The approximate solution derived here has been compared for condensation in various air-water vapour mixtures with the complete numerical solution of the governing equation in the fog layer. Numerous calculations indicate the reliability of this solution to condensation and evaporation, and applicability to most other vapours as well.

An alternative way of adequately describing heat and mass transfer in condensers and evaporators, allowing fog formation in the film and/or in the bulk flow, has been discussed in great detail. The recommended new procedure is illustrated by means of a flow chart. It corrects both the local transfer coefficients and direction of the bulk properties' path in the presence of both an induced velocity and fog 
formation (in the film and/or in the bulk of the mixture).

Acknowledgement-The author wants to thank the management of Akzo Research Laboratories Arnhem for their permission to publish this paper and Messrs H. P. Korstanje and G. Vegt for their support of this work. He also wants to express his gratitude to Prof. A. K. Chesters of Eindhoven University of Technology for his stimulating discussion on the subject.

\section{REFERENCES}

1. H. J. H. Brouwers and A. K. Chesters, Film modeis for transport phenomena with fog formation: the classical film model, Int. J. Ileat Mass Transfer 35, 1-11 (1992).

2. W. Piening, Die Wärmeübertragung an kalte Flachen bei freier Strömung, Beihefte Gesundheits-Ing. 1, 1-23 (1933) (in German).

3. E. T. Turkdogan, The theory of enhancement of diffusion-limited vaporization rates by a convection-condensation process, Part 1. Theoretical, Trans. Metall. Soc. A.I.M.E. 230, 740-750 (1964).

4. E. T. Turkdogan and K. C. Mills, The theory of enhancement of diffusion-limited vaporization rates by a convection condensation process, Part 2. Experimental, Trans. Metall. Soc. A.I.M.E. 230, 750-753 (1964).

5. D. E. Rosner, Enhancement of diffusion-limited vaporization rates by condensation within the thermal boundary layer, Int. J. Heat Mass Transfer 10, 1267-1279 (1967).

6. D. E. Rosner and M. Epstein, Fog formation conditions near cool surfaces, $J$. Coll. Interface Sci. 28, 60-65 (1968).

7. D. P. Sekulic̀, Irreversible condensation conditions near the cryosurface, Int. J. Heat Mass Transfer 28, 12051214 (1985).

8. M. Epstein and D. E. Rosner, Enhancement of diffusionlimited vaporization rates by condensation within the thermal boundary layer, Int. J. Heat Mass Transfer 13, 1393-1414 (1970)

9. Y. Hayashi, A. Takimoto and M. Kanbe, Transportreaction mechanism of mist formation based on the critical supersaturation model, J. Heat Transfer 98, 114-119 (1976).

10. Y. Hayashi, A. Takimoto and M. Kanbe, Mechanism of mist formation based on a critical supersaturation model in a turbulent convective field, Heat TransferJap. Res. 7, 14-25 (1978).

11. H. F. Johnstone, M. D. Kelley and D. L. McKinley, Fog formation in cooler-condensers, Ind. Engng Chem. 42, 2298-2302 (1950).

12. H. J. H. Brouwers, An improved tangency condition for fog formation in cooler-condensers, Int. J. Heat Mass Transfer 34, 2387-2394 (1991).

13. A. W. D. Hills and J. Szekely, Notes on vaporization into much colder surroundings, Chem. Engng Sci. 17, 79-81 (1964).

14. A. W. D. Hills and J. Szckcly, A note on the enhancement of the diffusion limited vaporization rates by condensation within the thermal boundary layer, Int. J. Heat Mass Transfer 12, 111-114 (1969).

15. H. L. Toor, Fog formation in boundary value problems, A.I.Ch.E. Jl 17, 5-14 (1971)

16. H. L. Toor, Fog vaporization and condensation in boundary value problems, Ind. Engng Fundam. 10, 121131 (1971).

17. K. M. Aref'yev and A. G. Averkiyev, Effect of fog formation at the evaporation surface on coefficients of heat and mass transfer during evaporative cooling of water, Heat Transfer-Sov. Res. 11, 143-147 (1979).
18. K. Hijikata and Y. Mori, Forced convective heat transfer of a gas with condensing vapor around a flat plate, Heat Transfer-Jap. Res. 2, 81-101 (1973).

19. F. Legay-Desesquelles and B. Prunet-Foch, Dynamic behaviour of a boundary layer with condensation along a flat plate: comparison with suction, Int. J. Heat Mass Transfer 28, 2363-2370 (1985).

20. F. Legay-Desesquelles and B. Prunet-Foch, Heat and mass transfer with condensation in laminar and turbulent boundary layers along a flat plate, Int. J. Heat Mass Transfer 29, 95-105 (1986).

21. Y. Hayashi, A. Takimoto and Y. Yamamoto, Heat and mass transfer with mist formation in a laminar duct flow, Heat Transfer-Jap. Res. 10, 37-51 (1981).

22. P. Koch, Warme- und Stofftransport bei laminarer freier Konvektion in feuchter Luft an einer gekühlten vertikalen Platte, D.Sc. Thesis, Technische Universität München (1986) (in German).

23. H. J. H. Brouwers, Film models for transport phenomena with fog formation, with application to plastic heat exchangers and condensers, D.Sc. Thesis, Eindhoven University of Technology (1990).

24. D. E. Steinmeyer, Fog formation in partial condensers, Chem. Engng Prog. 68, 64-68 (1972).

25. G. Hall and J. M. Watt, Modern Numerical Methods for Ordinary Differential Equations. Clarendon Press, Oxford (1976).

26. E. M. Sparrow, W. J. Minkowycz and M. Saddy, Forced convection condensation in the presence of noncondensables and interfacial resistance, Int. J. Heat Mass Transfer 10, 1829-1845 (1967).

27. R. C. Reid, J. M. Prausnitz and T. K. Sherwood, The Properties of Gases and Liquids, 3rd Edn. McGraw-Hill, New York (1977).

\section{APPENDIX}

Here the saturation line $F(t)$ of an air-water vapour mixture and the fog formation condition function $H(t)$ are derived. The saturation line follows from the thermally perfect gas law and Gibbs-Dalton's law as

$$
F(t)=\frac{P_{\mathrm{v}}}{P_{\mathrm{v}}+\frac{M_{\mathrm{n}}}{M_{\mathrm{v}}}\left(P_{\mathrm{tot}}-P_{\mathrm{v}}\right)} .
$$

In this paper the total pressure $P_{\text {tot }}$ amounts to 1.01325 bar, the saturation water vapour pressure is taken from Reid $e t$ al. [27], and the molecular mass of water vapour $M_{\mathrm{v}}=18.02$ $\mathrm{kg} \mathrm{kmol}{ }^{-1}$ and of air $M_{\mathrm{n}}=28.96 \mathrm{~kg} \mathrm{kmol}^{-1}$. In Fig. Al the resulting $F(t)$ is drawn.

In the case of fog formation equations (12) and (13) are coupled by relation (5). To determine the amount of pro-

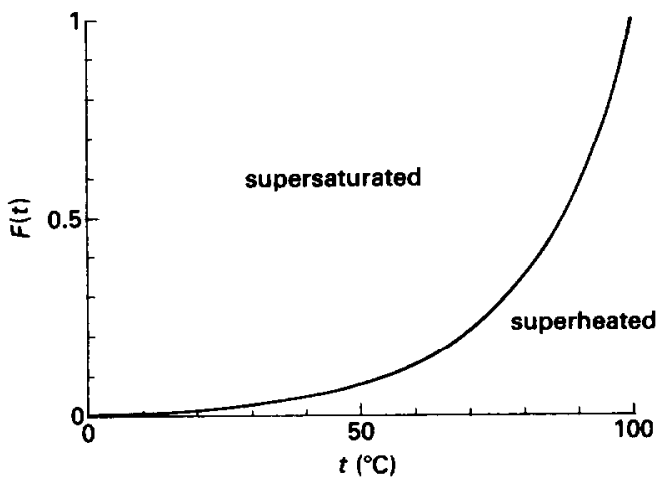

FIG. Al. The saturation line. 
duced fog, these equations are combined, yielding

$$
\frac{\mathrm{d}^{2} t}{\mathrm{~d} y^{2}}=\frac{\frac{H_{\text {lat }}}{c_{p, \mathrm{v}}} \frac{\mathrm{d}^{2} \ln (1-F)}{\mathrm{d} t^{2}}+\frac{\mathrm{d} \ln (1-F)}{\mathrm{d} t}}{L e_{\mathrm{v}}-\frac{H_{\text {lat }}}{c_{p, \mathrm{v}}} \frac{\mathrm{d} \ln (1-F)}{\mathrm{d} t}}\left(\frac{\mathrm{d} t}{\mathrm{~d} y}\right)^{2} .
$$

Equation (A2) is then substituted in equation (12) and equation (5) applied to produce

$$
K=\rho \mathbb{D} \frac{\left(L e_{\mathrm{v}}-1\right)\left(\frac{1}{1-F} \frac{\mathrm{d} F}{\mathrm{~d} t}\right)^{2}+L e_{\mathrm{v}} \frac{1}{1-F} \frac{\mathrm{d}^{2} F}{\mathrm{~d} t^{2}}}{L e_{\mathrm{v}}+\frac{H_{\mathrm{lat}}}{c_{p, \mathrm{v}}} \frac{1}{1-F} \frac{\mathrm{d} F}{\mathrm{~d} t}}\left(\frac{\mathrm{d} t}{\mathrm{~d} y}\right)^{2}
$$

The linearized form of equation (A3) for small $F$, with $L e=1$ substituted, corresponds to the expression ('equation (7)', $K$ is referred to as ' $r{ }_{3}$ ') of Toor [16] for the mass of fog formation per unit volume. The amount of fog formation is positive definite for $L e_{\mathrm{y}} \geqslant 1$, since $c=F(t)<1$ and the first and second derivalives of the function $F(t)$ with respect to $t$ are usually positive. The feature of $K$ being larger than zero for $L e_{v}=1$ has been employed implicitly by Aref'yev and Averkiyev [17]. For $L e_{v}<1$, however, the fog formation can become zero or even negative, thus fog formation ends. Mathematically fog formation in the film ends when the numerator of equation (A3) becomes zero (or negative)

$$
L e_{\mathrm{v}} \leqslant H(t)=\frac{\left(\frac{\mathrm{d} F}{\mathrm{~d} t}\right)^{2}}{\left(\frac{\mathrm{d} F}{\mathrm{~d} t}\right)^{2}+(1-F) \frac{\mathrm{d}^{2} F}{\mathrm{~d} t^{2}}}
$$

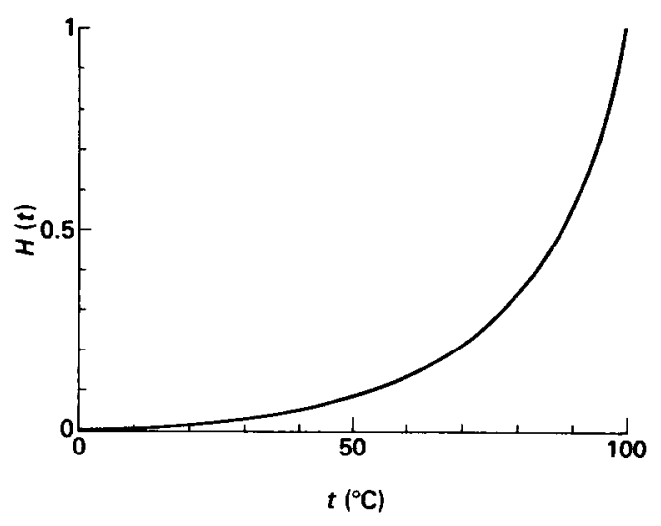

FIG. A2. The fog formation condition line.

In Fig. A2 this fog condition function $H(t)$, which depends on the saturation line $F(t)$ only, is drawn with application of equation (A1). To permit $K>0$ in a fog film $L e_{v}$ must be larger than the maximum $H(t)$ of the film. Toor [16] assumed implicitly that $K>0$ in analysing fog formation of dilute water vapour in air $\left(c \leqslant 0.035, t \leqslant 35^{\circ} \mathrm{C}\right)$. This assumption appears to be correct a posteriori, since $L e_{v} \cong 0.5$ for the mixtures considered and hence $H(t)<L e_{v}$ in the film (see Fig. A2).

\section{MODFI.ES DF. FILM POUR LES PHENOMENES DE TRANSPORT AVEC FORMATION DE BROUILLARD: LE MODELE DU FILM DE BROUILLARD}

Résumé - La supersaturation éventuelle dans un film et dans le coeur d'un mélange binaire a été précédement discutée dans un article (Brouwers et Chesters, Int. J. Heat Mass Transfer 35, 1-11 (1992)). On détermine ici les conditions exactes de la formation du brouillard, l'intensité du brouillard et les régions surchauffées dans le film. Les équations de la diffusion et de l'énergie (couplées avec les conditions de saturation) dans la couche de brouillard sont résolues numériquement. Différents mélanges de vapeur d'eau et d'air illustrent l'effet de la formation de brouillard sur les transferts de chaleur et de masse. Une analyse asymptotique de l'équation de la couche de brouillard fournit une excellente solution approchée. Cette solution conduit à des facteurs de correction du modèle analytique du film pour les effets combinés sur le transfert de la formation de brouillard et de l'injection/succion. Le modèle de film de brouillard est enfin appliqué a l'écoulement en conduite d'un mélange binaire. Cette approche donne de nouvelles procédures pour le calcul des condenseurs et évaporateurs avec à la fois du brouillard dans le film (ce qui affecte les taux de transfert) et/ou dans le coeur du fluide (ce qui affecte les bilans globaux de masse et d'énergie).

\section{FILMMODELLE FÜR TRANSPORVORGÄNGE MIT NEBELBILDUNG : DAS NEBEL- FILMMODELL}

Zusammenfassung - In einer früheren Arbeit (Brouwers and Chesters, Int. J. Heat Mass Transfer 35, 111 (1992)) wurde die Möglichkeit einer Übersättigung in einem Film und in der Kernströmung eines binären Gemisches diskutiert. In der vorliegenden Analyse werden die genauen Bedingungen für eine Nebelbildung und für die Größe der Bereiche mit Nebelbildung und Überhitzung im Film bestimmt. Im nächsten Schritt werden die grundlegenden Gleichungen für den Stoff- und den Energietransport in der Nebelschicht (gekoppelt mit der Sättigungsbedingung) numerisch gelöst. Berechnungen mit verschicdencn Gemischen von Wasserdampf und Luft zeigen den erheblichen Einfluß der Nebelbildung auf den Wärmeund Stofftransport. Eine eingehende asymptotische Analyse der grundlegenden Gleichung für die Nebelschicht führt zu einer hervorragend angepaßten Näherungslösung. Aus dieser Lösung ergeben sich Korrekturfaktoren für das analytische Filmmodell, welche die kombinierten Einflüsse der Nebelbildung und einer Absaugung/Einspritzung auf die Transportvorgänge berücksichtigen. Abschließend wird das NebelFilmmodell auf eine Kanalströmung eines binären Gemisches angewandt. Dieses Verfahren liefert eine neue Vorgehensweise bei der Auslegung von Kondensatoren und Verdampfern, in denen sowohl Dampfbildung im Film (Einfluß auf die Transportvorgänge) und/oder im Kern der Strömung (Einfluß auf die globale Stoff- und Energiebilanz) auftreten kann. 


\title{
ПЛЕНОЧНЫЕ МОДЕЛИ ЯВЛЕНИЙ ПЕРЕНОСА С ТУМАНООБРАЗОВАНИЕМ: ПЛЕНОЧНАЯ МОДЕЛЬ ТУМАНА
}

\begin{abstract}
Аннотация-В ранее опубликованной работе обсуждалось возможное перенасыщение пленки и объема бинарной смеси. В данной статье сначала определяются условия и интенсивность образования тумана, а также областей перенасыщения в пленке, а затем проводится численное решение определяющих уравнений диффузии и энергии (совместно с условиями насыщения) для слоя тумана. Оценка различных смесей воды, пара и воздуха показывает существенное влияние туманообразования на скорости тепло- и массообмена. В результате тщательного асимптотического анализа определяющих уравнений для слоя тумана получено приближенное решение, которое пает прекрасное совпадение с экспериментом. Кроме того, это решение позволяет получить поправочные коэффициенты для аналитической пленочной модели, учитывающие влияние туманообразования и вдува/отсоса на скорости переноса. Наконец, пленочная модель тумана применяется к течению бинарной смеси в канале. Этот подход дает возможность полу чить новые методы расчета конденсаторов и испарителей, в которых учитываются как туманообразование в пленке (влияющее на скорости переноса), так и/или в объеме жидкости (влияющее на общий баланс массы и энергии).
\end{abstract}

